\title{
Aeolian Features on Venus: Preliminary Magellan Results
}

\author{
Ronald Greeley,' Raymond E. ARvidson, ${ }^{2}$ Charles Elachi, ${ }^{3}$ Maureen A. Geringer, ${ }^{1}$ JefFrey J. Plaut, ${ }^{3}$ \\ R. STEPHEN SAUNDERS, ${ }^{3}$ GERALD SCHUBERT, ${ }^{4}$ ElLEN R. STOFAN, ${ }^{3}$ ERIC J.P. ThOUVENOT, ${ }^{3.5}$ \\ STEPHEN D. WALL, ${ }^{3}$ AND CATHERINE M. WEITZ ${ }^{3}$
}

\begin{abstract}
Magellan synthetic aperture radar data reveal numerous surface features that are attributed to aeolian, or wind processes. Wind streaks are the most common aeolian feature. They consist of radar backscatter patterns that are high, low, or mixed in relation to the surface on which they occur. A data base of more than 3400 wind streaks shows that low backscatter linear forms (long, narrow streaks) are the most common and that most streaks occur between $17^{\circ} \mathrm{S}$ to $30^{\circ} \mathrm{S}$ and $5^{\circ} \mathrm{N}$ to $53^{\circ} \mathrm{N}$ on smooth plains. Moreover, most streaks are associated with deposits from certain impact craters and some tectonically deformed terrains. We infer that both of these geological settings provide fine particulate material that can be entrained by the low-velocity winds on Venus. Turbulence and wind patterns generated by the topographic features with which many streaks are associated can account for differences in particle distributions and in the patterns of the wind streaks. Thus, some high backscatter streaks are considered to be zones that are swept free of sedimentary particles to expose rough bedrock; other high backscatter streaks may be lag deposits of dense materials from which low-density grains have been removed (dense materials such as ilmenite or pyrite have dielectric properties that would produce high backscatter patterns). Wind streaks generally occur on slopes $<2^{\circ}$ and tend to be oriented toward the equator, consistent with the Hadley model of atmospheric circulation. In addition to wind streaks, other aeolian features on Venus include yardangs(?) and dune fields. The Aglaonice dune field, centered at $25^{\circ} \mathrm{S}, 340^{\circ} \mathrm{E}$, covers $\sim 1290 \mathrm{~km}^{2}$ and is located in an ejecta flow channel from the Aglaonice impact crater. The Meshkenet dune field, located at $67^{\circ} \mathrm{N}$, $90^{\circ} \mathrm{E}$, covers $\sim 17,120 \mathrm{~km}^{2}$ in a valley between Ishtar Terra and Meshkenet Tessera. Wind streaks associated with both dune fields suggest that the dunes are of transverse forms in which the dune crests are perpendicular to the prevailing winds. Dunes on Venus signal the presence of sand-size $(\sim 60$ to $2,000 \mu \mathrm{m})$ grains. The possible yardangs are found at $9^{\circ} \mathrm{N}, 60.5^{\circ} \mathrm{E}$, about $300 \mathrm{~km}$ southeast of the crater Mead. Although most aeolian features are concentrated in smooth plains near the equator, the occurrence of wind streaks is widespread, and some have been found at all latitudes and elevations. They demonstrate that aeolian processes operate widely on Venus. The intensity of wind erosion and deposits, however, varies with locality and is dependent on the wind regime and supply of particles.
\end{abstract}

\section{INTRODUCTION}

Aeolian, or wind-related, processes on the surface of Venus have been debated for more than two decades, and many investigators predicted that aeolian features would eventually be found (reviewed by Greeley and Arvidson [1990]). Although images of the surface returned from Soviet Venera landers and measurements of near-surface winds suggested local modification of the surface by wind, definitive evidence for more widespread aeolian activity was not observed until the Magellan mission [Saunders et al., 1991]. Preliminary analyses of Magellan radar images revealed several regions where wind-related features are abundant, as well as other isolated occurrences [Arvidson et al., 1991].

For this report, about $44 \%$ of the surface of Venus has been searched in a reconnaissance mode for wind-related features

\footnotetext{
${ }_{1}^{1}$ Department of Geology, Arizona State University, Tempe.

2 Department of Earth and Planetary Sciences, Washington University, St. Louis, Missouri.

3 Jet Propulsion Laboratory, Pasadena, California.

${ }^{4}$ Department of Earth and Space Sciences, Institute of Geophysics and Planetary Physics, University of California, Los Angeles.

${ }^{5}$ Centre National de la Recherche Scientifique, Toulouse, France.
}

Copyright 1992 by the American Geophysical Union.

Paper number 92JE00980.

0148-0227/92/92JE-00980\$05.00 using (primarily) cycle 1 Magellan radar data (Figure 1). Aeolian features include possible (1) dune fields, (2) yardangs (wind-eroded hills), and (3) various types of wind streaks (surface patterns of contrasting radar backscatter cross sections). We describe these aeolian features and their characteristics as seen on Magellan radar images and assess the geological settings and properties of the surface in which they occur. We also discuss the possible modes of formation of the most common aeolian features (wind streaks), drawing on terrestrial examples, Martian analogs, and results from wind tunnel simulations. We then consider the relationships between aeolian features and patterns of atmospheric circulation on Venus.

\subsection{Background}

Wind-related features observed on planetary images provide direct evidence for the interaction of the atmosphere with the surface. The presence of depositional aeolian features, such as dunes, shows areas where particles capable of movement by the wind occur and gives indications of weathering processes. The identification of the type and orientation of aeolian features provides clues to the physical properties of surface materials where they occur and the wind direction at the time of their formation. Assessment of their age provides insight into past wind regimes and climates.

Wind streaks are among the most common aeolian feature observed on planetary surfaces. They occur on Earth, Mars, Triton, and Venus. On Earth, wind streaks are surface 


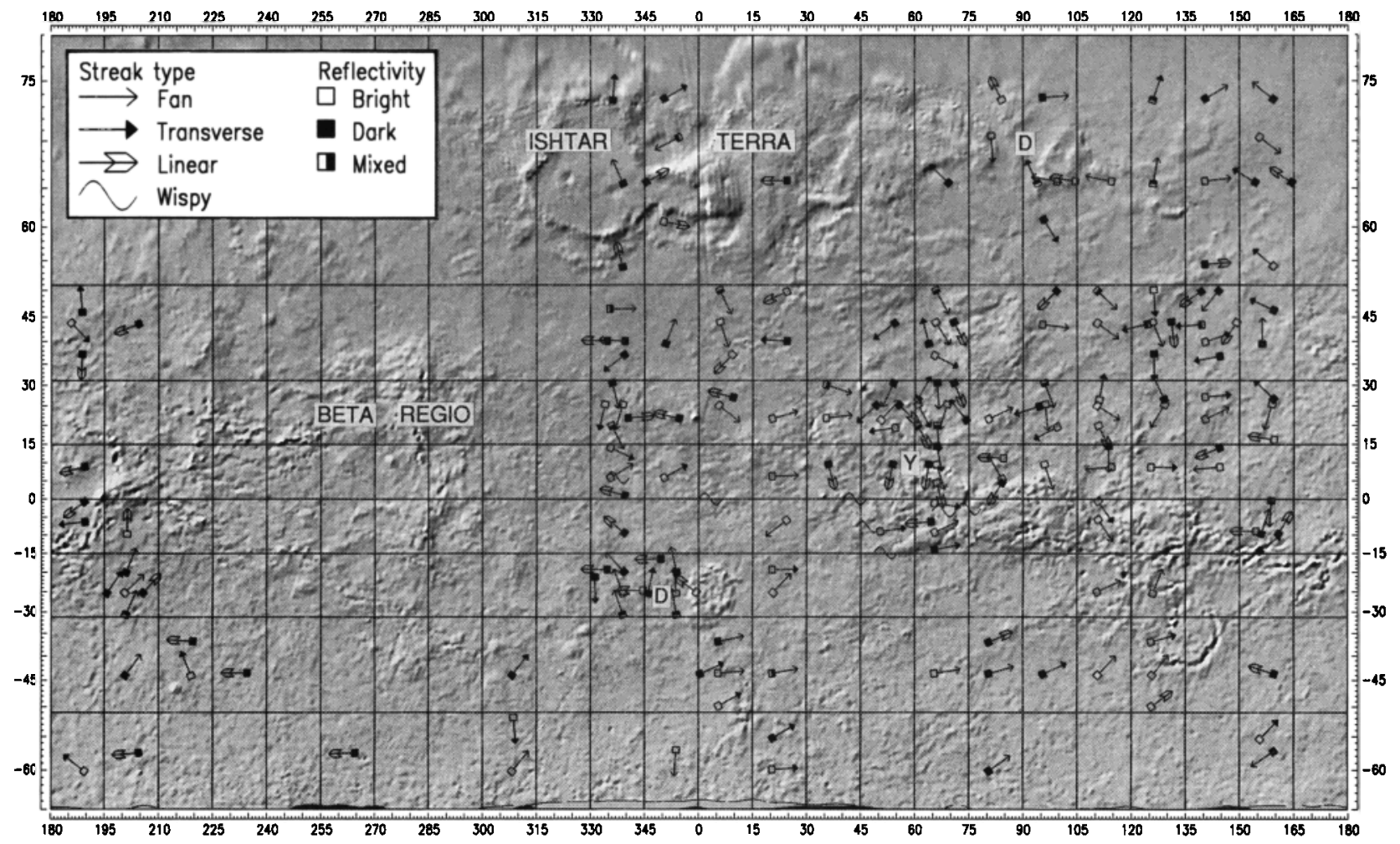

Fig. 1. Map of Venus showing orientation of wind streaks equal-area by latitude and longitude "bin" and their distribution. Symbols are given in the center of each bin, or positioned within the bin to maximize legibility. Arrows indicate inferred downwind direction. Also shown are the location of dune (D) and yardang (Y) fields. Regions not yet analyzed on F-BIDRs include longitude $\sim 30^{\circ}$ through $50^{\circ}$ (superior conjunction) and longitudes $\sim 160^{\circ}$ through $330^{\circ}$ (digital base map from U.S. Geological Survey).

patterns in which loose materials commonly $<1 \mathrm{~m}$ thick are distributed by sediment-moving winds. Typically, they are associated with wind patterns and turbulence generated by topographic features such as small hills. On Earth and Mars, wind streaks are visible on optical images because of albedo contrasts related to particle size or composition and to exposures of bedrock. Wind streaks are also visible on Earth on radar images [Greeley et al., 1989; Saunders et al., 1990], where factors such as bedrock exposures and sediment cover result in contrasting radar backscatter cross sections. Wind streaks on Earth range in length from a few centimeters for small sand drifts behind rocks to more than $15 \mathrm{~km}$ for patterns developed in the lee of hills and small mountains (Figures 2a-2d) and in association with impact craters (Figure
$2 h$. Wind streaks of several types also occur on Mars (Figures $2 e$ and 2f), as reviewed by Greeley et al. [1992]. Thomas et al. [1981] derived a classification of Martian wind streaks based on (1) their upwind sources (sediment deposit or topographic obstacle), (2) their albedo contrast (bright or dark) in relation to the background surface, and (3) special morphologic or compositional features. Some, termed variable features, appear, disappear, or change their size, shape, and orientation on time scales of weeks to years [Thomas and Veverka, 1979, etc.]. Martian wind streaks range in length from a few centimeters at the Viking landing sites to $115 \mathrm{~km}$ for a dark, plume-shaped streak in the Mesogaea region [Veverka et al., 1976].

Regardless of type, mode of formation, or planet where they

Fig. 2. (Opposite) Typical wind streaks on Earth, Mars, and Venus; arrows indicate prevailing wind direction. (a) Amboy, Califomia, optical image showing cinder cone ( $460 \mathrm{~m}$ in diameter) and dark streak. Prevailing wind is from the west (left); general background consists of pahoehoe basaltic lava flows and is mantled with windblown sand (white areas). Area of streak is dark basalt swept free of sand due to wind turbulence shed from flow around the cone (from Greeley and Iversen [1987]; air photo AXL-26K-36 taken January 10, 1953). (b) Seasat radar image (revolution 882) of Amboy, California, showing radar-bright streak corresponding to dark areas on Figure $2 a$ that is relatively free of windblown sand. Dark areas correspond to concentrations of sand and (extending toward the top of the picture from the cone) basalt pebbles and cinders. Radar illumination from the bottom. (c) SIR-A radar image of the Altiplano, Bolivia, showing radar-dark streaks as long as $15 \mathrm{~km}$ formed in association with hills (bright features). Contrasts in radar backscatter cross sections result from differences in sand mantles, dune forms, and vegetation, all related to erosion and deposition patterns generated by wind flow around the hills. Prevailing winds are from the Pacific Ocean to the west (left) (SIR-A: DT-31). (d) SIR-A radar image of linear streaks southeast of Laskar Gan, Afghanistan, formed predominantly in sedimentary deposits, including playa silts and clays. Prevailing winds are from the northeast (marked with an arrow), which funnel through a gap in a low ridge and then spread out to the southwest. Contrasts in radar backscatter cross section evidently result from differences in the distribution of sediments (SIR-A: DT-35/36). (e) Dark wind streaks on Mars in the Phoenicis Lacus region; prevailing wind is from the southeast (left). These and similar dark wind streaks are considered to result from 

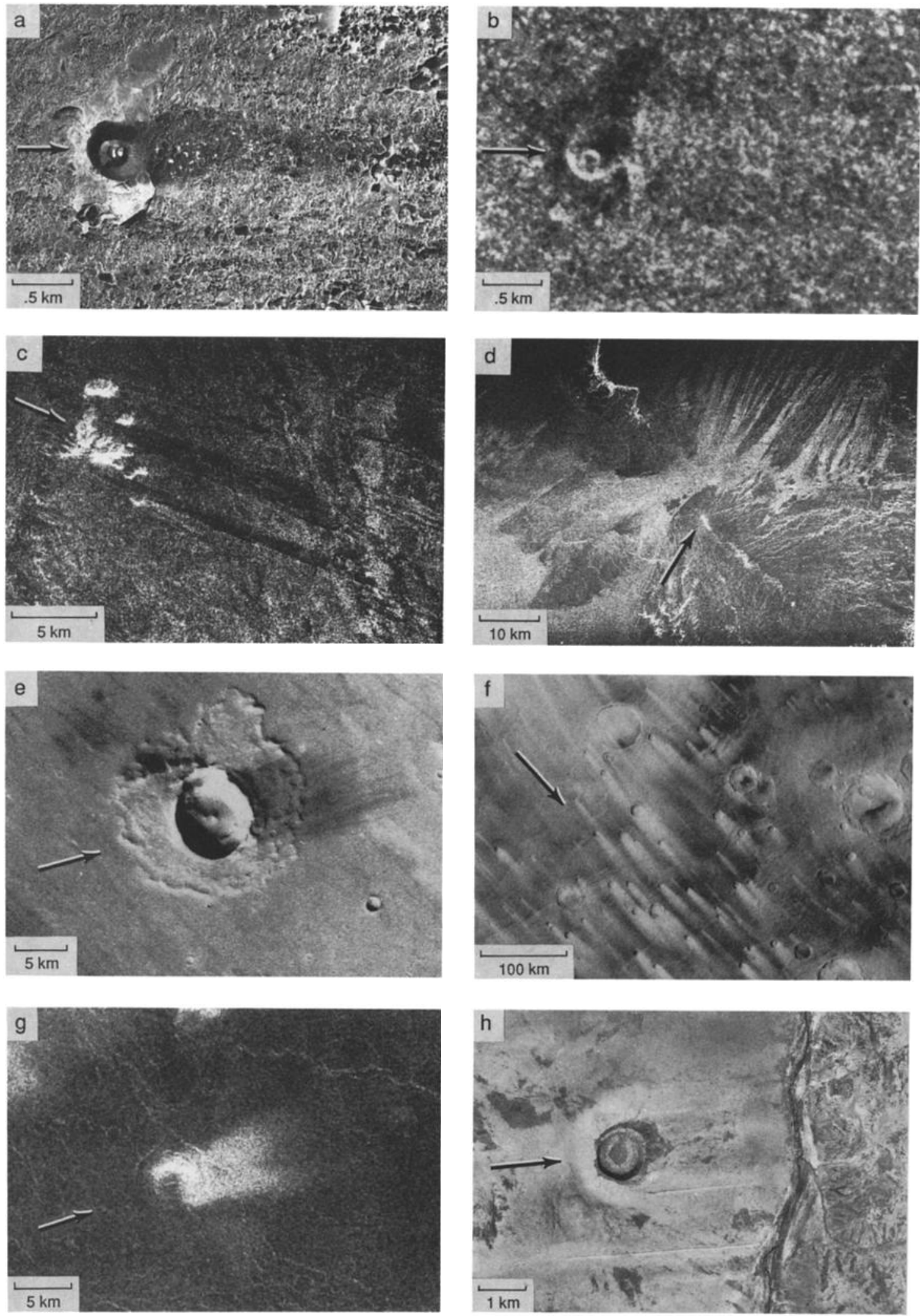

erosion. Area shown is 30 by $43 \mathrm{~km}$ (Viking Orbiter 459A79). (f) Bright wind streaks in the Hesperia Planum, Mars; prevailing winds are from the northwest (upper left). Bright wind streaks are thought to be dust deposited in the lee of topographic features, perhaps under stable atmospheric conditions. Area shown is about $500 \mathrm{~km}$ across (Viking Orbiter 453A35). (g) Radar-bright wind streak on Venus at $23.9^{\circ} \mathrm{S}, 345.1^{\circ} \mathrm{E}$. Streak is about $10 \mathrm{~km}$ long, is associated with a small hill, and occurs within the "parabolic collar" associated with the impact crater Carson (see Figure 19); wind flow at the time of streak formation is inferred to have been from the south (left). Radar illumination from the top (Magellan F-MIDR 25S345). (h) Wolf Creek impact crater, Australia, showing associated sand deposits (bright areas) and erosional areas (dark zones); ridges are linear dunes parallel to the wind; prevailing winds are from the east (left); area shown is $\sim 6 \mathrm{~km}$ by $9 \mathrm{~km}$ (Commonwealth of Australia photograph, Billiluna E52-14). 
occur, there is near-unanimous agreement that wind streaks represent the prevailing wind direction at the time of their formation. As such, they can be used as local "wind vanes" to map near-surface winds and have been used to assess local, regional, and global pattems of atmospheric circulation on Mars [Sagan et al., 1972; Thomas and Veverka, 1979; Greeley et al., 1992].

The discovery of wind streaks on Venus (Figure $2 g$ ) as described by Arvidson et al. [1991] affords the opportunity to learn about the interaction of the atmosphere and surface, both for the identification of sediments capable of being moved by the wind and in mapping near-surface winds. Mapping winds is especially important because of the paucity of observational constraints on the circulation in the lower atmosphere [Schubert, 1983]. For example, Doppler tracking of Venera probes and landers [Marov et al., 1973; Antsibor et al., 1976; Keldysh, 1977; Kerzhanovich et al., 1979; Moroz, 1981; Kerzhanovich and Marov, 1983] and tracking of the Pioneer Venus probes [Counselman et al., $1979,1980]$ provided estimates of zonal and meridional wind speeds as high as several meters per second to an altitude of $\sim 10 \mathrm{~km}$. Surface winds measured by Veneras 9 and 10 [Avduevskii et al., 1976] were 0.3 to $1 \mathrm{~m} \mathrm{~s}^{-1}$. The observed motions in the lowest scale height are sluggish but appear to be neither mainly meridional nor zonal. However, the available measurements are inadequate for even approximating the patterns of lower atmospheric circulation [Schubert, 1983]. Above $10 \mathrm{~km}$, zonal wind speeds increase monotonically with altitude, and the dominant circulation is a westward zonal superrotation [Schubert et al., 1980].

Although the lower atmospheric circulation of Venus may be temporally and spatially complex, it is useful to consider two end-member models of the circulation (Figure 3). One is a Hadley circulation that redistributes solar energy absorbed in the lower atmosphere and at the ground near the equator [Stone, 1974, 1975; Kálney de Rivas, 1973, 1975; Schubert et al., 1980; Rossow, 1983; Schubert, 1983]. This direct meridional circulation is symmetric about the equator and involves equatorward surface winds, upflow over the equator, poleward winds aloft, and downflow at high latitudes. The long-term, zonally averaged circulation of the deep atmosphere of Venus may resemble a Hadley circulation. The existence of a Hadley cell in the lower atmosphere of Venus can be evaluated using Magellan images of wind streaks in this study. Should a Hadley cell exist, wind streaks might also provide information on the latitudinal extent of the circulation.

A second possible model of the lower atmosphere on Venus involves diurnal circulation. In this model (Figure 3), there is downflow over the subsolar region just above the surface, flow toward the antisolar region near the surface, upflow over the antisolar region just above the surface, and flow toward the subsolar point aloft [Dobrovolskis and Ingersoll, 1980; Covey et al., 1986]. This is an "anti-Halley cell" above which (in the lower atmosphere) is a simple, thermally direct subsolar-to-antisolar circulation pattern, with upflow in the subsolar region (Halley cell, Figure 3 ). Wind streaks in this model would be oriented away from the warm, dayside of Venus and toward the cooler night region. This circulation pattern would be more difficult to detect using wind streaks than a Hadley cell because the movement of the subsolar point over the surface ( 1 Venus solar day = 117 Earth days) would change wind streak directions with time. However, it

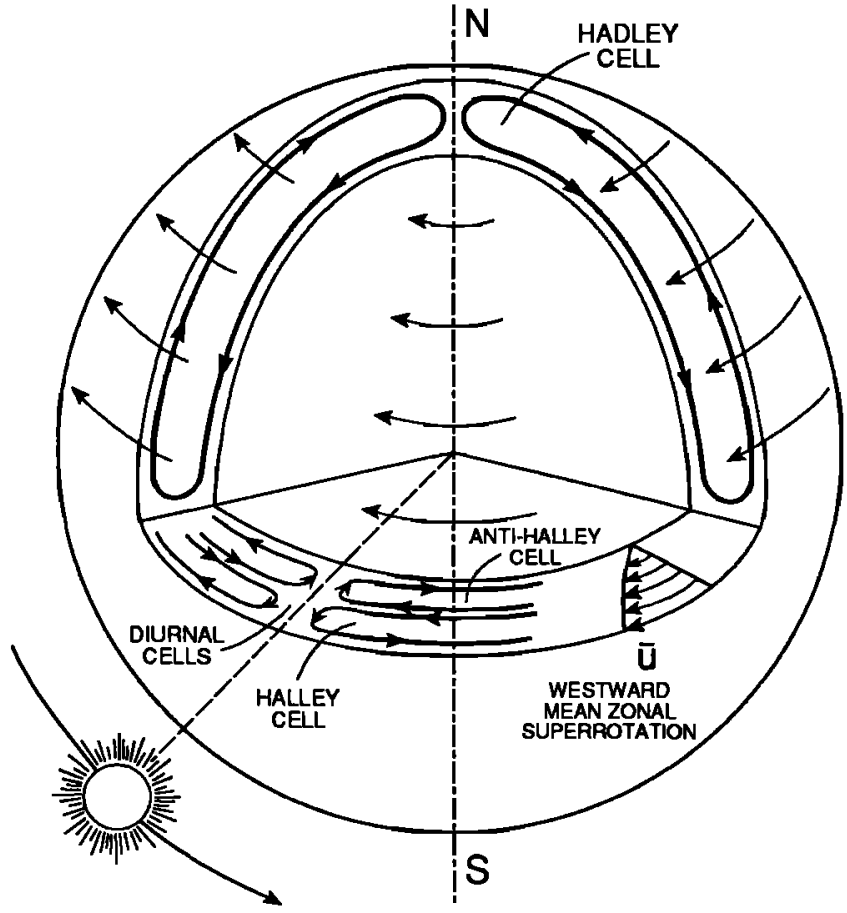

Fig. 3. Sketch of possible circulation patterns in the atmosphere of Venus. The mean zonal velocity $\bar{u}$ is a westward superrotation. The magnitude of $\bar{u}$ increases with height above the surface. The meridional Hadley circulation may not extend to the poles. Centers of convergence and divergence in the diumal Halley and anti-Halley circulations may not occur at noon. The diumal circulations have other flow components not shown here.

is conceivable that such changes could be detected with multiple Magellan observations over time, as are planned in future mapping cycles. Moreover, as noted by Saunders et al. [1991] strongest, winds were predicted to flow to the west, away from the solar noon longitude, and to flow down hill. These predictions can be addressed with Magellan data.

\subsection{Methodology}

Observations for Venusian aeolian features included searches of synthetic aperature radar (SAR) images, assessment of surface properties and elevations where features were found, and correlations of aeolian features with local geology. The search for wind-related features was conducted using F-BIDRs (full resolution basic image data record), F-MIDRs (full resolution mosaiked image data record), and C1-MIDR (mosaiked image data record, compressed once) (see Saunders et al. [1990, this issue] and Pettengill et al. [1991] for explanation of data products). The best spatial resolution on F-BIDR and MIDR images is $150 \mathrm{~m} /$ line pair (represented by $75 \mathrm{~m} / \mathrm{pixel}$ ). F-BIDR prints through orbit 1319 were examined for small $(<10 \mathrm{~km}$ ) features (Figure 1). Aeolian features $>10 \mathrm{~km}$ were assessed on F-MIDRs and C1-MIDRs; consequently, because not all data have been assembled as mosaics, some larger features may not yet be recognized in the areas analyzed for smaller features using only F-BIDRs. The distribution of aeolian features was plotted on a global scale and correlated with local and regional geologic settings to place constraints on the possible sources for the deposits associated with the features.

In identifying aeolian features such as wind streaks, it is important to note that BIDRs and MIDRs have brightness 
values that are proportional to specific radar backscatter cross section ( $\sigma_{0}$ which is cross section per unit area divided by the average value for the relevant incidence angle and converted to decibels). An understanding of the behavior of $\sigma_{0}$ as a function of incidence angle and look azimuth is critical to interpretations of the radar appearance of aeolian features. The incidence angle for Magellan data varies systematically with the latitude, from a value of $43^{\circ}$ at the periapsis latitude $\left(10^{\circ} \mathrm{N}\right)$ to a value of $18^{\circ}$ at the north pole. In general, in this range of incidence angles, radar wavelength-scale roughness appears to dominate the cross-section values of the aeolian features discussed here, with secondary control by topography and dielectric properties. However, the identification of wind streaks in the SAR images at high northern and southern latitudes may be more difficult, because subtle differences in small-scale roughness are more difficult to detect at small incidence angles. Blom and Elachi $[1981,1987]$ have shown that the azimuth of the radar viewing geometry may also substantially affect the visibility of aeolian bedforms such as sand dunes. Continuing analysis of data from future mapping cycles of Magellan with different incidence angle and look azimuth profiles will allow a complete assessment of the streak population on Venus.

In addition to the high-resolution specific backscatter cross section data obtained by the Magellan SAR, estimates of surface emissivity, Fresnel reflectivity, and rms slope (at greater than wavelength scales) with $\sim 10 \mathrm{~km}$ resolution were obtained by the radar system in its radiometric and altimetric modes, respectively [Pettengill et al., 1991]. Emissivity and Fresnel reflectivity of geologic materials are closely tied to the dielectric constant and thus allow model-dependent separation of the effects of roughness and dielectric properties on the SAR signatures [Tyler et al., 1991]. These observations provide information on the physical properties of surface materials.

Magellan altimetric data enabled assessment of topographic control of aeolian features. Pettengill et al. [this issue] derived a global topographic map of about $5 \mathrm{~km}$ spatial resolution and $<100 \mathrm{~m}$ vertical resolution. For our analyses of wind streaks, the elevation of each streak was determined and the local slopes were assessed, using a bilinear interpolation of the topographic data points within a $10-\mathrm{km}$ radius of the streak origin. However, these statistics are based on a preliminary global topographic map which contains some errors. As shown in Figure 4, the azimuth of the maximum slope $(\beta$, in the downslope direction, i.e., "dip" direction) and the amount (magnitude) of the slope in degrees from the horizontal were determined. Finally, the angle $(\gamma)$ between streak and slope azimuth was determined in order to assess whether streaks tend to be oriented upslope, downslope, or randomly with respect to slope.

\section{WIND STREAKS}

Wind streaks of several forms have been found on Venus. Although it is tempting to derive a formal classification,
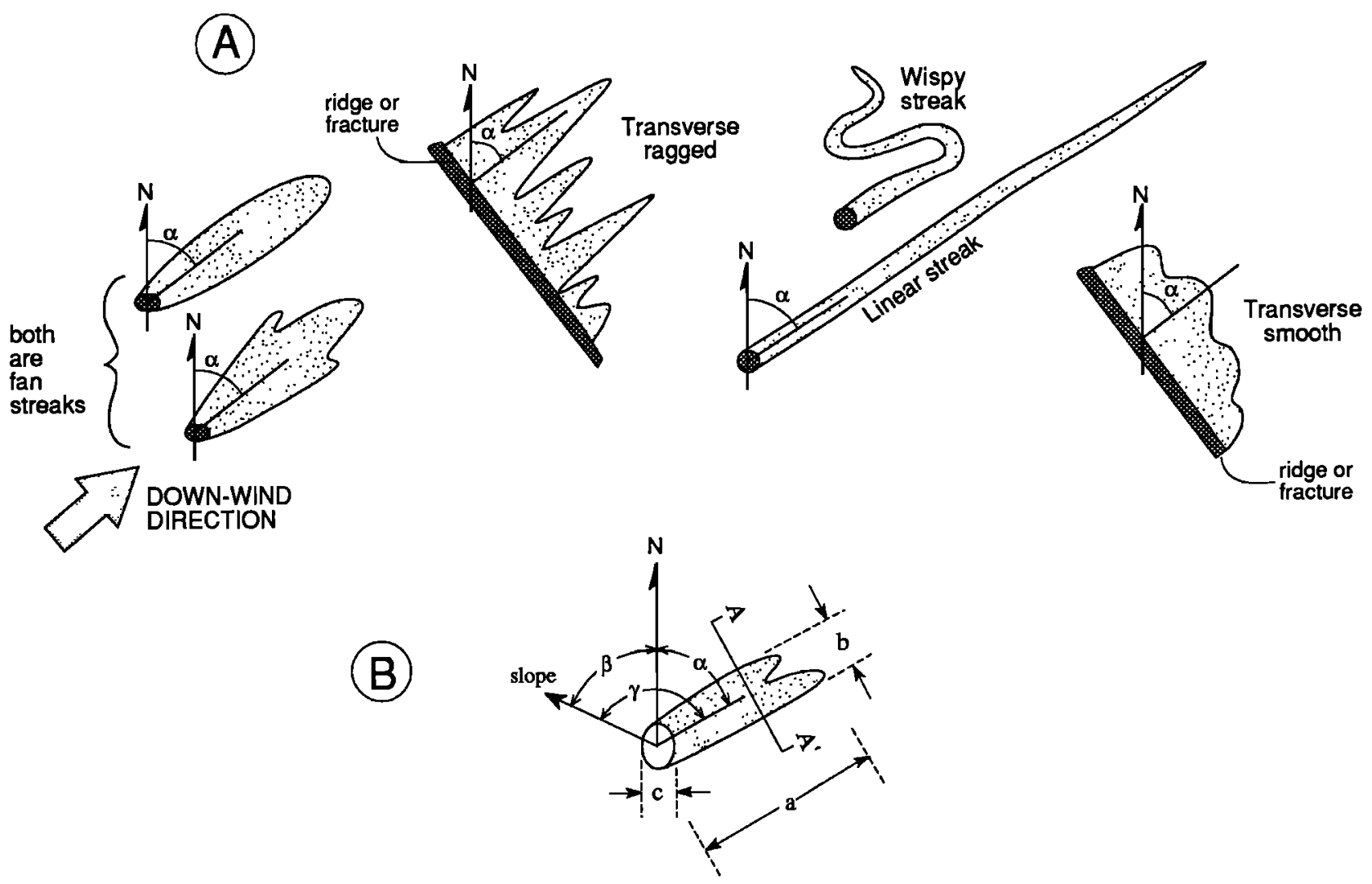

Fig. 4. (a) Planform shapes and terms applied to Venusian wind streaks; $\alpha$ is the azimuth measured from north to the streak in the inferred downwind direction. (b) Parameters used in analysis: $a$ is streak length (maximum) parallel to inferred wind direction, $b$ is streak width (maximum) normal to length, $c$ is diameter of landform with which streak is associated (or the average width of the ridge or trench for transverse streaks), $\alpha$ is azimuth of streak in the inferred downwind direction, $\beta$ is azimuth of terrain in the downslope direction, and $\gamma$ is minimum angle between streak azimuth and slope azimuth $\left(\leq 180^{\circ}\right)$, A- $A^{\prime}$ indicates the line along which radar backscatter cross section profiles were obtained for some streaks. 
TABLE 1. Parameters used in Data Base to Describe Wind Streaks on Venus

\begin{tabular}{ll}
\hline Principal parameter & Sub-type \\
\hline Planimetric shape & Fan \\
& Linear \\
& Transverse \\
& Wispy \\
& Bright \\
Radar reflectivity & Mixed \\
& Cone \\
& Hill \\
Landform origin & Crater \\
& Ridge \\
& Trench \\
& Length \\
& Width \\
Planimetric measurements & Azimuth \\
& Landform diameter (or width) \\
& Geologic setting \\
& Elevation \\
& Local slope direction \\
& Local slope magnitude \\
&
\end{tabular}

See text for explanations.

such a derivation would be premature until the full range of possibilities is known upon completion of mapping by Magellan. Table 1 shows the parameters that appear to be important in describing Venusian wind streaks. A data base is being compiled which includes these parameters and descriptions of the terrain, topography, and surface properties in which the streaks occur. Each streak is "tagged" in the data base by the latitude and longitude of its inferred (upwind) point of origin, using best available positional information. Aeolian features in some areas occur as multiple streaks. For such areas, one entry is made in the data base, along with an estimate of the total number of individual streaks. The values of length, width, etc., given are estimated to represent the set, but the estimates are not based on a rigorous statistical analysis.

\subsection{Wind Streak Description}

The shape of the streak in planform is considered to be a primary descriptive characteristic. Five shapes are commonly found: fans, linear streaks, wispy streaks, transverse-ragged streaks, and transverse-smooth streaks (Figures 4 and 5). Fan-shaped streaks have a variety of outlines and are often associated with landforms such as small hills (Figures $5 a-5 c$ ). Transverse streaks typically occur in sets along fractures or ridges oriented perpendicular to the inferred wind direction, and may be either ragged (serrated) or smooth in outline (Figures $5 d$ and $5 e$ ). Linear streaks (Figures $5 f$ and $5 g$ ) typically are more than 20 times longer than their width and often occur in sets of a half dozen or more similar streaks. Wispy streaks are wavy, meanderous patterns that vary in width along their length (Figure $5 h$ ). Wispy streaks are often associated with ridges and impact craters. Many of the wispy streaks associated with ridges are parallel to (and have the same length as) the ridge. Wispy streaks associated with impact craters occur in sets of a half dozen or more and form a meanderous pattern approximately radial to the crater or crater deposit. However, for most wispy streaks it is not possible to determine which end is the apparent source, nor is it feasible to determine a meaningful orientation (azimuth) because of their meanderous character.

Contrasts in radar specific backscatter cross section between the streak and the background enable wind streaks to be identified. Bright streaks are brighter than the background on which they occur (Figures $5 a$ and $5 e$ ), dark streaks are darker than the background (Figures $5 b, 5 d, 5 g$ and $5 h$ ), and mixed streaks (Figure $5 c$ ) have both bright and dark components (generally a bright interior and a dark "halo", set on a background of intermediate specific cross section). All wispy streaks are radar-dark (Figure $5 h$ ). Nearly all linear streaks are radar-dark, most fan-shaped streaks are radar-bright, and transverse ragged streaks are nearly equally radar-dark, -bright, and -mixed (Figure 6a). However, some linear streaks and transverse-ragged streaks occur in multiple sets and create a bright and dark pattem in which it is impossible to separate dark streaks on a bright background from bright streaks on a dark background (the "zebra" effect, Figure 5f).

The landform with which the wind streak is associated is also considered in the descriptions where appropriate. Cones are conical in topographic cross section and commonly have summit craters; hills are more rounded, typically lack summit craters and include domical cross sections; craters are circular depressions and may show evidence of modest raised rims; trenches are linear features of negative relief; and ridges are linear features of positive relief. The small widths of trenches and ridges make it difficult in most cases to distinguish between the two on SAR images. Some wind streaks occur on otherwise featureless plains and are not associated with obvious landforms.

The parameters shown in Table 1 were used in the assessment for each wind streak found. Measurements (Figure $4 b$ ) were made for the maximum length and width of the streak (length was taken to be the axis of the streak oriented parallel with the inferred wind direction), the diameter of the landform (somewhat arbitrary for some hills and cones that merge with the surrounding plain) or width of the trench or ridge where determination was possible. The streak azimuth (i.e., degrees from north) in the downwind direction was also measured. The terrain in which streaks and other aeolian features occur was assessed for general geology, using preliminary units defined by Saunders et al. [1991]. Backscatter cross sections were obtained in lines across selected streaks, perpendicular to their axes.

Following the method outlined above, more than 3400 streaks have been identified on Venus thus far in the analysis of Magellan data.

\subsection{Wind Streak Distribution}

The distribution of wind streaks was assessed in relation to type, streak length, latitude, elevation on Venus, and the slope and slope direction (downslope) of the surfaces on which they occur. Distributions of the azimuths of wind streaks were also determined for comparisons with models of atmospheric circulation. These distributions include the estimated total number of streaks in areas where multiple features occur except for the distributions by elevation, slope, and azimuth. As shown in Figure $6 a$, dark linear streaks are the most common, whereas dark transverse smooth streaks are the least common, with only one having been found. 

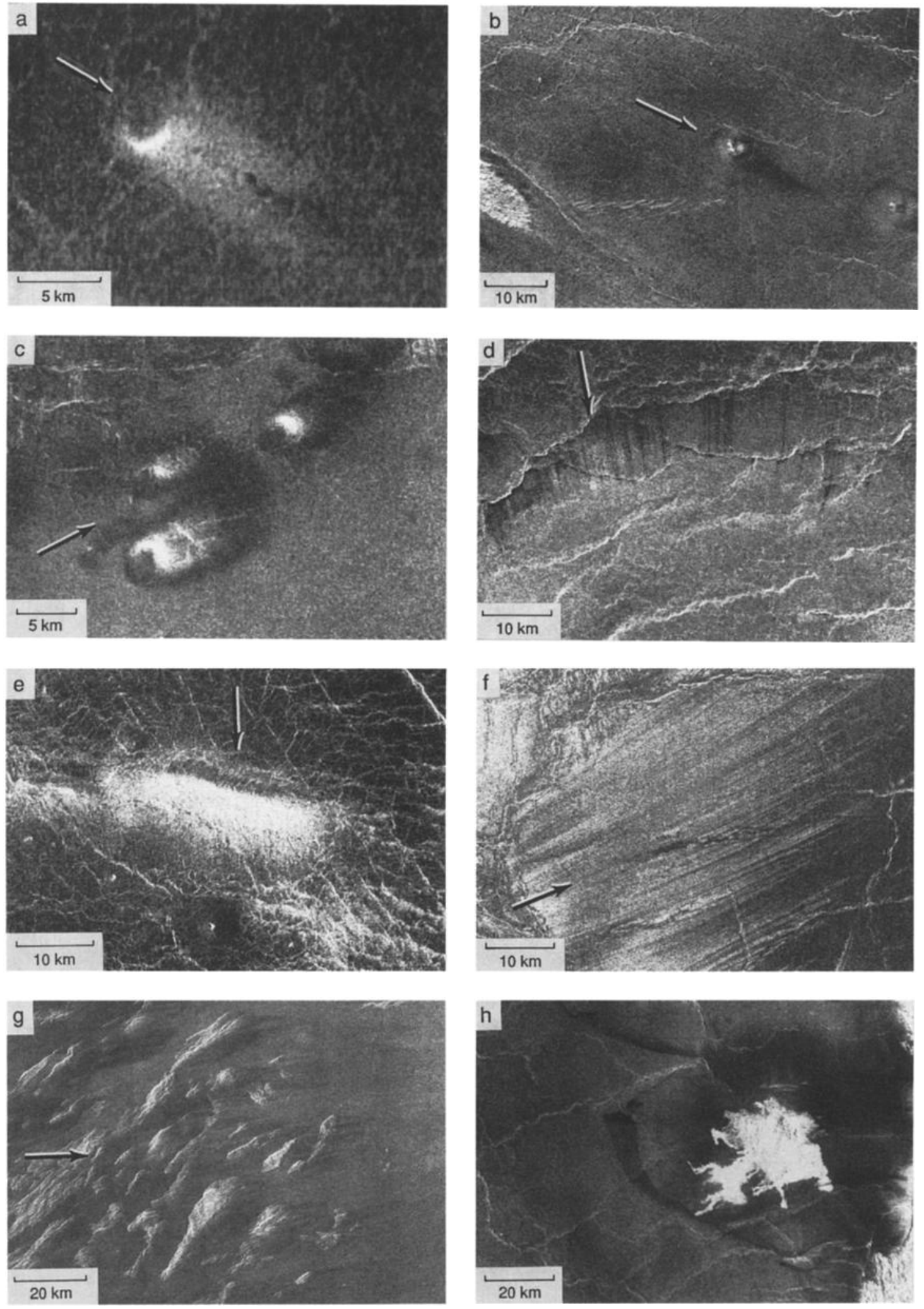

Fig. 5. Venus wind streaks (arrows indicate inferred downwind direction). (a) Radar-bright fan-shaped wind streak $10.5 \mathrm{~km}$ long associated with a small hill in eastem Niobe Planitia, centered at $36.5^{\circ} \mathrm{N}, 174.6^{\circ} \mathrm{E}$ (Magellan F-BIDR 1194). (b) Radar-dark fan-shaped wind streak about $10 \mathrm{~km}$ long associated with a small hill centered at $29.4^{\circ} \mathrm{N}, 57^{\circ} \mathrm{E}$ (Magellan MRPS 40983). (c) Radar-bright and -dark (mixed) fan-shaped wind streak in the Carson crater area, centered at $23^{\circ} \mathrm{S}, 344.9^{\circ} \mathrm{E}$. Area shown is about 25 by $36 \mathrm{~km}$ (Magellan F-MIDR 23S345). (d) Transverse ragged wind streak (radar-dark) associated with a ridge system in southem Leda Planitia, centered at $37.5^{\circ} \mathrm{N}, 65.5^{\circ} \mathrm{E}$; area shown is about 44 by $64 \mathrm{~km}$ (Magellan MRPS 38883). (e) Transverse smooth wind streak (radar-bright) associated with a ridge in Guinevere Planitia, centered at $26.2^{\circ} \mathrm{N}, 331.4^{\circ} \mathrm{E}$; area shown is about 39 by $57 \mathrm{~km}$ (Magellan F-MIDR 25N333). (f) Multiple linear streaks in the vicinity of Mead crater, centered at $15^{\circ} \mathrm{N}$, $65^{\circ} \mathrm{E}$; area shown is about 44 by $64 \mathrm{~km}$ (Magellan MRPS 37877). (g) Multiple linear streaks (radar-dark) in western Aphrodite, centered at $0.9^{\circ} \mathrm{S}, 71.1^{\circ} \mathrm{E}$; area shown is 82 by $120 \mathrm{~km}$ (Magellan F-MIDR 00N070). (h) Radar-dark wispy streak in eastern Sedna Planitia, centered at $37^{\circ} \mathrm{N}, 2^{\circ} \mathrm{E}$; area shown is about 87 by $128 \mathrm{~km}$ (Magellan C1-MIDR 30N009). 


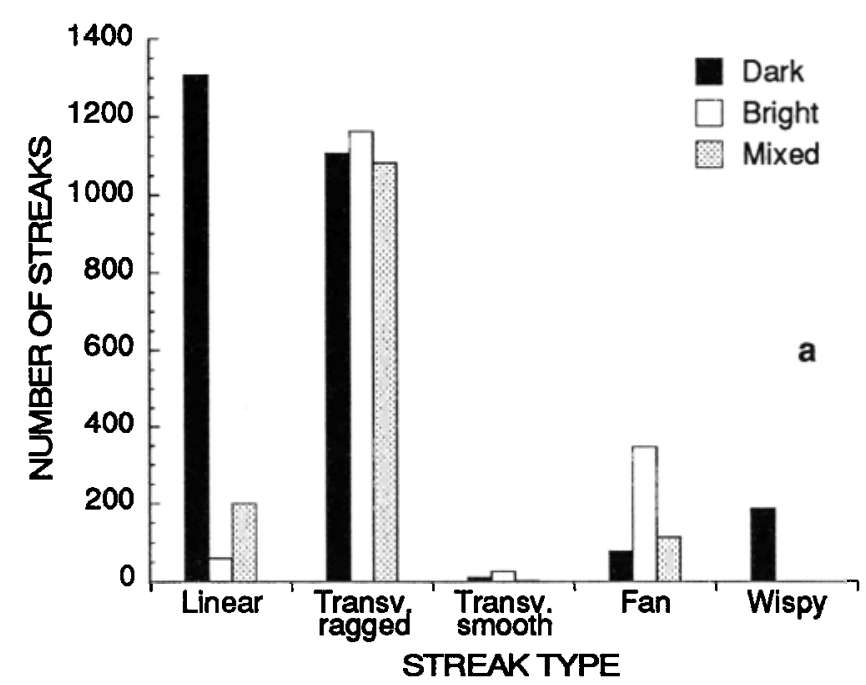

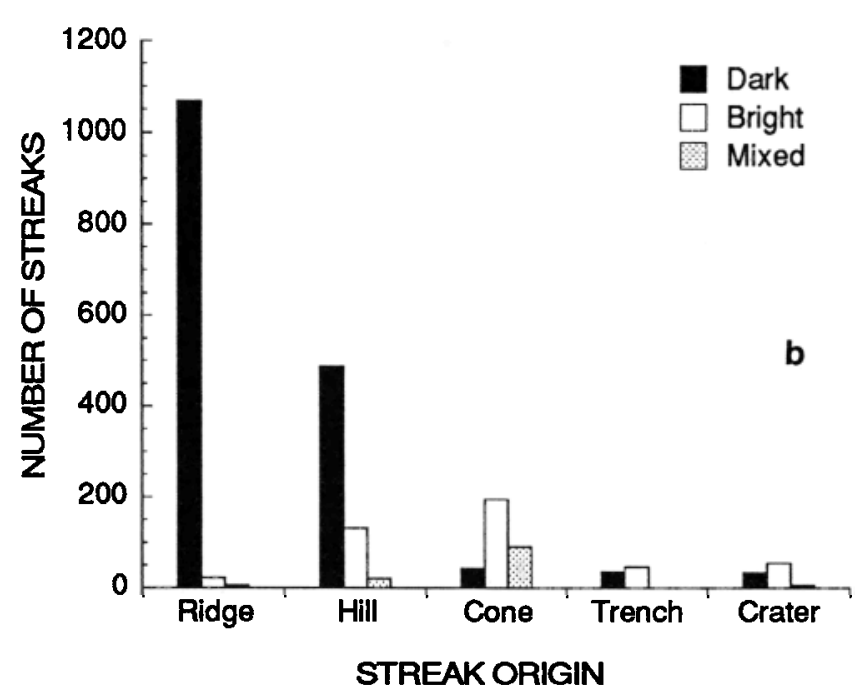

(b) Histograms of the type of ' landforms with which streaks are associated.

Figure $6 b$ shows the distribution of radar-dark, -bright, and -mixed backscatter cross section and the landform with which they are associated. Most radar-dark streaks (mostly linear forms) occur in association with ridges, whereas most radarbright streaks are found with small hills and cones. Assessment of strength lengths shows that dark linear streaks are the longest $(>100 \mathrm{~km})$, whereas most bright fan-shaped streaks are $<10 \mathrm{~km}$ long.

Figure 7 shows that streaks occur over a broad range of latitudes with peaks in the latitude bands $23^{\circ} \mathrm{S}$ to $30^{\circ} \mathrm{S}$ and $23^{\circ} \mathrm{N}$ to $30^{\circ} \mathrm{N}$. Many streaks occur in clusters associated with ejecta deposits from impact craters in plains east of Alpha Regio, southern Guinevere Planitia, and in eastern Aphrodite Terrae (Figure 1). No assessment was made of the distribution of streaks with longitude because the Magellan coverage by longitude was incomplete at the time of this study.

Figure 8 shows distributions of streaks with elevation, slope magnitude, and slope-streak angle. Because many streaks are $>10 \mathrm{~km}$ long, the elevation, slope, and angle may change as a function of distance along the streak. For a given spacecraft orbit there is a variable offset between the

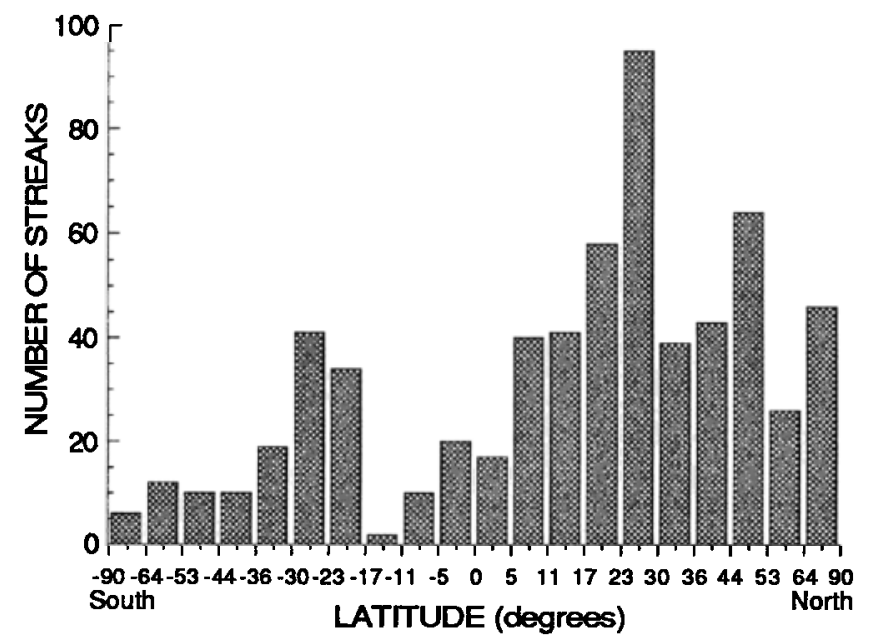

Fig. 7. Distribution of streaks (of all types) by equal-area bands of latitude. location of the altimetry data acquisition (nadir) and the location of SAR and radiometry data acquisition. Consequently, where gaps in Magellan data occur, they affect data at different locations on the planet. Where no altimetry data are present for a streak, the streak was not included in elevation distributions. Moreover, where altimetry data were missing in the slope calculation region, the streak was omitted in both slope magnitude and slope azimuth distributions. Because of these considerations, the distributions shown in Figure 8 contain considerably less than the total number of streaks in the data base. Finally, where comparative global distributions are shown, the two curves are normalized to have equal areas.

Figure $8 a$ shows the distribution of elevations for streaks relative to $6051 \mathrm{~km}$ (the reference elevation on Venus, taken from the center of the planet) and the distribution of all elevations determined by the Magellan altimetry experiment [Pettengill et al., this issue]. Results show that streaks form at nearly all elevations. Figure $8 b$ shows that most streaks form on surfaces of low slope, equal to or only slightly steeper than average slopes on Venus. The distribution of the smallest angle between downslope direction and streak

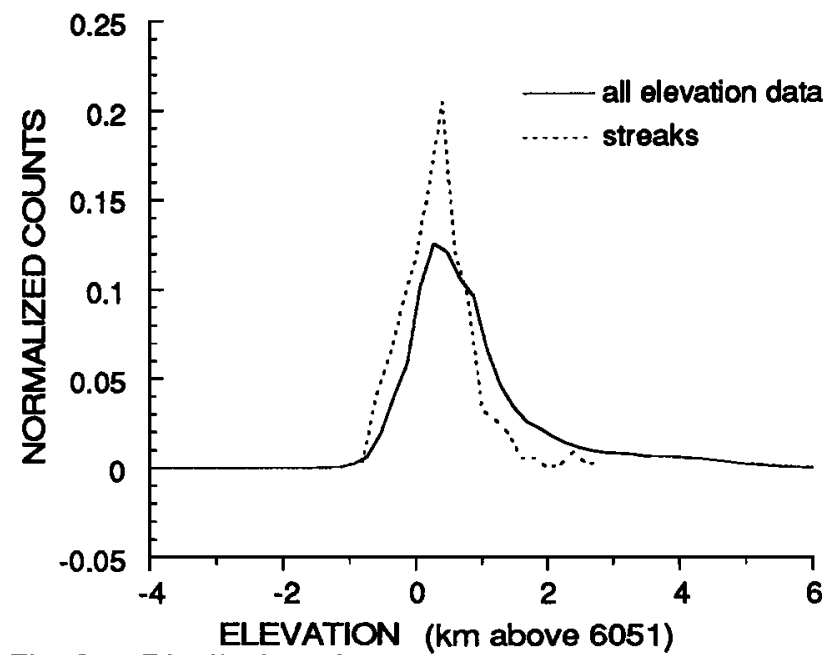

Fig. 8a. Distribution of streaks by elevation on Venus; curves are normalized to unit area under each. 


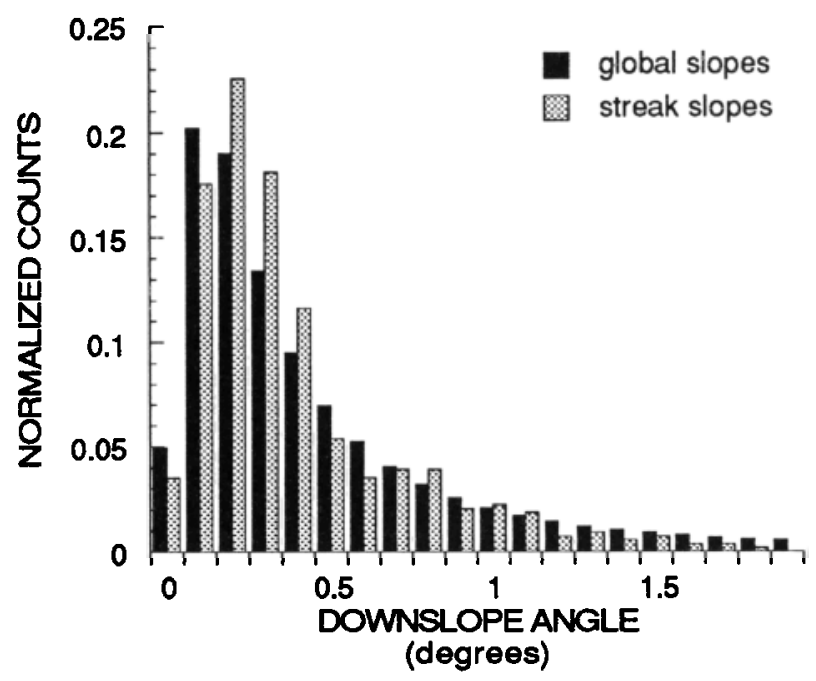

Fig. $8 b$. Distribution of streaks by slope magnitude at $10 \mathrm{~km}$ scale; curves are normalized to unit area under each.

direction (Figure $8 c$ ) reveals that streaks form at nearly all angles to the local slope, with only a slight preference for down slope orientation. However, in some places there is a correlation with local slope. For example, streaks in the Ovda region tend to be oriented upslope, as discussed later.

Figure 9 shows the distribution of streak azimuths in the northern and southern hemispheres. Streaks in the northern hemisphere suggest formative winds predominantly from the north toward the equator (azimuths mainly between $\sim 120^{\circ}$ and $250^{\circ}$ ). Very few wind streaks in the southern hemisphere have azimuths between $\sim 90^{\circ}$ and $270^{\circ}$, indicating a preponderance of inferred wind directions toward the equator.

\subsection{Temporal Changes}

During the second cycle of Magellan radar mapping, 51 orbits of data with the same left-looking geometry as those in cycle 1 were acquired. Using data from these orbits, the northern Navka Region was studied to determine if any of the streaks found in cycle 1 had changed. The region covers $10^{\circ}$ to $30^{\circ} \mathrm{N}$, and $329^{\circ}$ to $336^{\circ} \mathrm{E}$ longitude. Most of the streaks found in this region during cycle 1 are radar-bright and -mixed

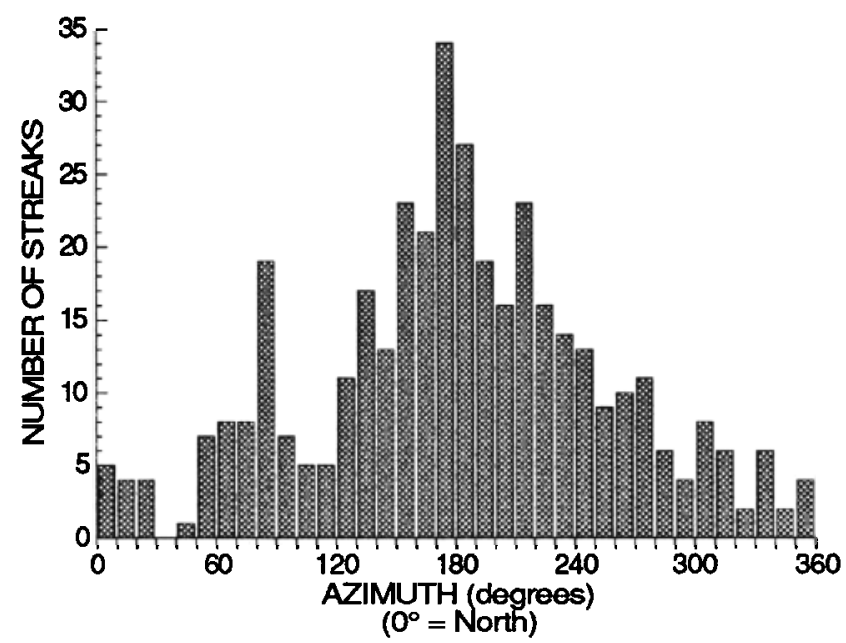

Fig. 9a. Distribution of streaks by azimuth (inferred downwind direction) in the northern hemisphere.



Fig. 8c. Distribution of streaks in relation to slope direction ( $\gamma$ $=0^{\circ}=$ downslope, $\gamma=180^{\circ}=$ upslope).

fan-shaped streaks associated with small cones, although there are also some transverse-smooth bright streaks associated with ridges. Comparisons of F-BIDRs and FMIDRs from both cycle 1 and 2 showed no apparent changes in the streaks during the eight months between acquisition of spacecraft data.

\subsection{Wind Streak Formation}

Study of wind streaks in the planetary context began with their discovery on Mars in the early 1970s [Sagan et al., 1972, 1973]. Various investigations have been made of Martian features [Veverka et al., 1977], terrestrial analogs [Greeley and Iversen, 1986], wind tunnel simulations [Iversen and Greeley, 1984], and atmospheric conditions [Veverka et al., 1981] in an attempt to understand the formation and evolution of wind streaks.

Most wind streaks on Earth and Mars are associated with topographic obstacles and form in response to wind patterns and turbulence developed around the obstacles. Dark (low optical albedo) Martian streaks represent either bedrock areas swept free of loose particles or lag deposits of coarse grains

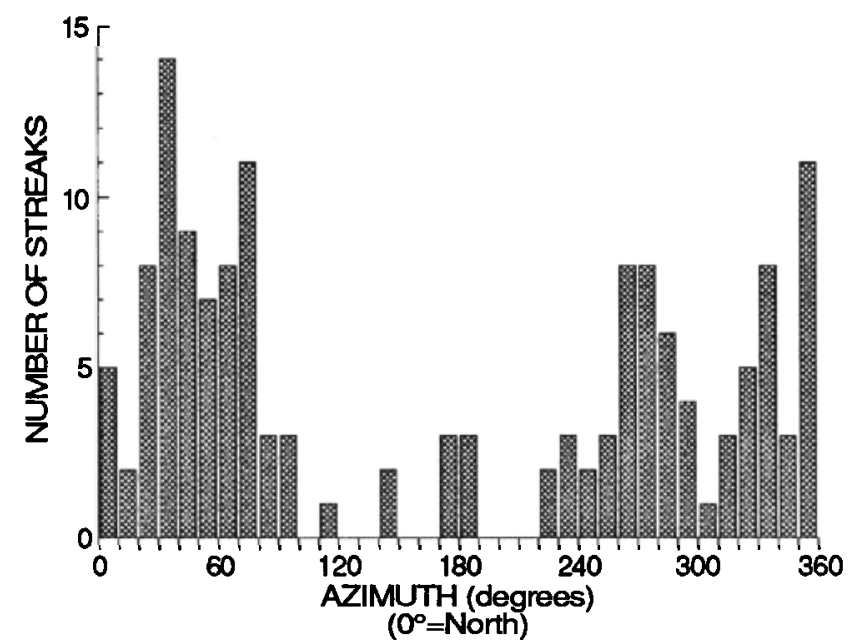

Fig. $9 b$. Distribution of streaks by azimuth (inferred downwind direction) in the southern hemisphere. 
from which smaller, brighter particles have been deflated. Bright Martian streaks are considered to be dust deposited in the lee of topographic obstacles to the wind, perhaps under conditions of atmospheric stability [Veverka et al., 1981]. The albedo contrast of Martian streaks can be explained by deposits of sediment as thin as a few microns [Thomas et al., 1981, 1984; Lee, 1984]. Under most circumstances, deposits this thin would be penetrated by radar energy, and the streaks would not be seen on Magellan images. On the other hand, the estimates of sediment thickness for the Martian streaks are only lower limits, and they could be much thicker.

What are the requirements for wind streaks to be visible on radar images? The backscatter signatures of aeolian features may indicate one of several possible modes of origin, some of which can be assessed quantitatively or by analogy to features on other planets (Table 2). At full resolution, the ability to detect features by their contrast in radar backscatter is limited primarily by coherent noise ("speckle"). The minimum detectable contrast ratio in Magellan SAR images allows identification of streaks in which radar specific cross section differs from the surrounding material by $\sim 1 \mathrm{~dB}$ or more, with better than $67 \%$ confidence. This corresponds to $\sim 10 \%$ change in returned power. In general, for Magellan radar, energy returned from a surface depends on (1) surface slope relative to the incoming radiation at the scale of the SAR resolution (for Magellan, $\sim 150$ to $300 \mathrm{~m}$, depending on latitude), (2) surface roughness at the scale of the SAR wavelength (for Magellan, $12.5 \mathrm{~cm}$ ) averaged over a resolution element, and (3) the complex dielectric constant of the material. For Venusian wind streaks to be visible in Magellan images as a consequence solely of slopes requires a physically improbable (in some cases, unrealistic) surface. Thus, the radar contrast between streaks and the surrounding terrain could result either from differences in roughness or in dielectric constant. Radar discrimination of observed terrestrial wind streaks, such as those shown in Figures $2 a-2 d$, are due primarily to roughness differences. On Venus, regional context often provides insight into the responsible mechanism. We consider roughness differences related to sediment cover to explain the radar contrast for most Venusian wind streaks, although in some cases such interpretation is ambiguous and differences in dielectric constant may be involved.

Figure 10 shows a region of Venus where insight may be gained into the thickness of windblown material forming radar-dark streaks. It shows a radar-bright crater outflow deposit (inferred to be rough) overlain with several radar-dark wind streaks. The most plausible explanation is that the windblown material forms a smooth, homogeneous layer over the flows and absorbs some of the radar energy, leading to a decrease in backscatter from the underlying flow. Using a simple model of a homogeneous layer over a rough surface (neglecting surface refraction effects and assuming that the layer has a low dielectric constant), the change in backscatter $(\Delta \sigma)$ due to the overlying layer is given by

$$
\Delta \sigma=\frac{8.7}{\cos \theta} \frac{H}{L}
$$

in which $\theta$ is the incidence angle, $L$ is the penetration depth of the material, and $H$ is the thickness [Elachi et al., 1984]. For the area shown in Figure $10, \theta=43^{\circ}$ and $\Delta \sigma$ for the streaks ranges from 2 to $6 \mathrm{~dB}$. Assuming a loss tangent of 0.005 to 0.01 [Campbell and Ulrichs, 1969], this leads to a penetration depth of -0.6 to $1.2 \mathrm{~m}$ and a corresponding minimum layer of particles composing the dark streak of 0.1 to $0.7 \mathrm{~m}$ thick, well within the range for wind streaks observed on Earth but thicker than the minimums inferred for Mars. Consequently, the Venusian features may form over much longer time scales than Martian features, which can change in as little as $\sim 38$ days.

TABLE 2. Wind Streaks: Hypotheses and Tests

\begin{tabular}{|c|c|c|}
\hline Streak Type & Possible Origin & Tests \\
\hline \multirow[t]{10}{*}{ Bright } & High reflectivity & \\
\hline & 1. Mineralogy & Emissivity, reflectivity anomaly. \\
\hline & 2. Bulk density (welding) & \\
\hline & Roughness & \\
\hline & 1. Rough deposit & RMS slope value (if "fractal"). \\
\hline & Microdunes & RMS slope value (if "fractal"). \\
\hline & Scoured surface (bedrock or lag) & Association with obstacles; "window" effect. \\
\hline & $\begin{array}{l}\text { 4. Nondeposition (assuming smooth deposit } \\
\text { off streak) }\end{array}$ & "Shadow" effect possible in streak setting? \\
\hline & $\begin{array}{l}\text { Radar penetration with enhanced scatter from } \\
\text { subsurface interface }\end{array}$ & \\
\hline & 1. Smooth deposits overlying rough substrate & $\begin{array}{l}\text { Consistent with necessary conditions? (inclination } \\
\text { angle, dielectric, etc.) }\end{array}$ \\
\hline \multirow[t]{8}{*}{ Dark } & Low reflectivity & \\
\hline & 1. Low density deposit (soil, pumice) & Emissivity, reflectivity anomaly. \\
\hline & 2. Lossy material & Emissivity, reflectivity anomaly. \\
\hline & Smoothness & \\
\hline & $\begin{array}{l}\text { 1. Soil filling in or covering roughness } \\
\text { elements }\end{array}$ & Possible sources, gradational contacts. \\
\hline & Smooth sheet of rock & Superposition, morphology (margins). \\
\hline & 3. Exhumation of smooth surface & Association with obstacles; "window" effect. \\
\hline & $\begin{array}{l}\text { 4. Nondeposition (assuming rough deposit off } \\
\text { streak) }\end{array}$ & "Shadow" effect possible in streak setting? \\
\hline
\end{tabular}




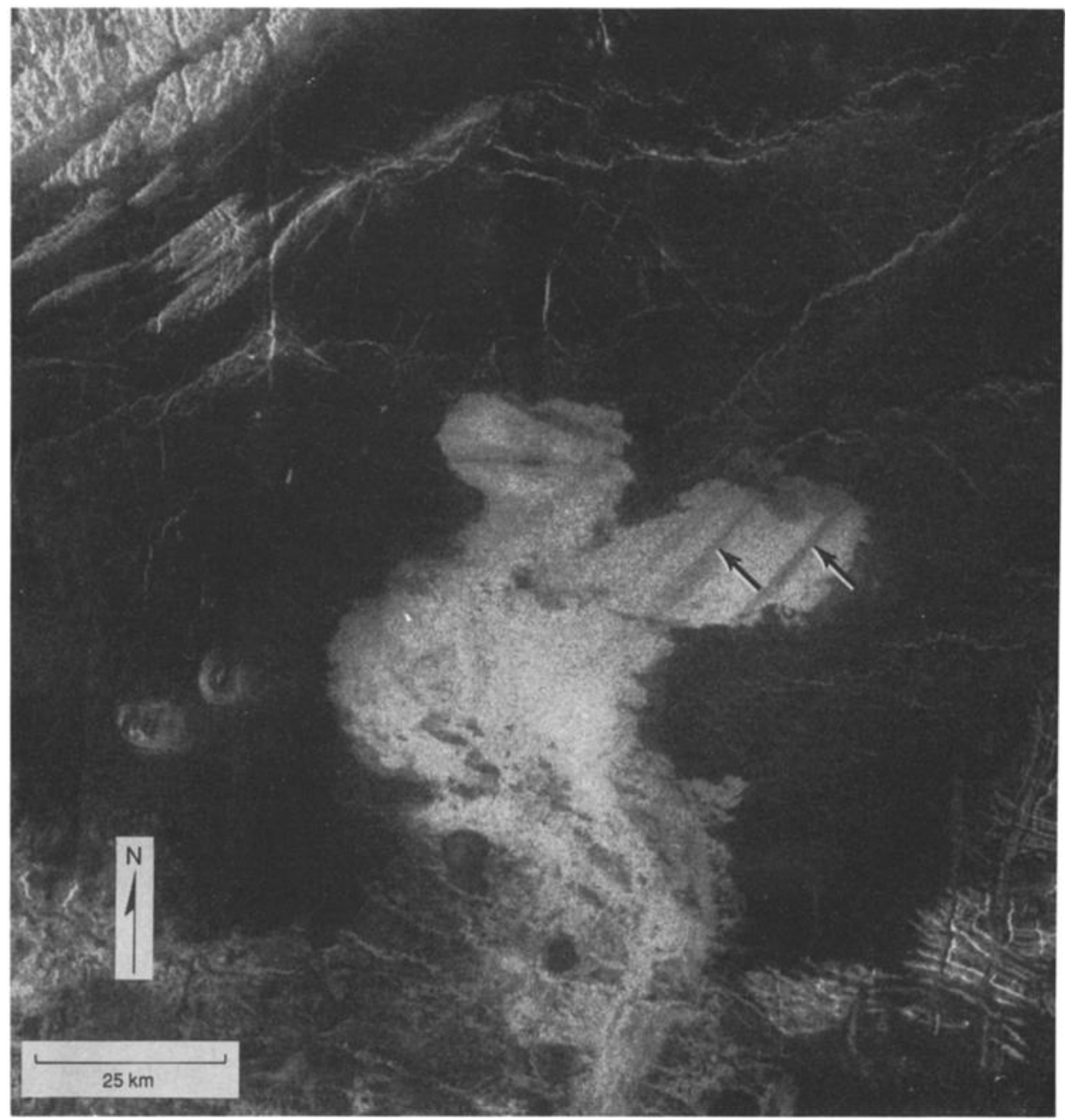

Fig. 10. Part of western Niobe Planitia showing radar-dark streaks (arrows) superposed on radar-bright crater outflow deposits. The outflows are associated with the $42-\mathrm{km}$-diameter crater Manzolini. Radar-dark material forming the streaks is estimated to be 0.1 to $0.7 \mathrm{~m}$ thick; area shown is centered at $26.5^{\circ} \mathrm{N}, 93.5^{\circ} \mathrm{E}$ (Magellan $\mathrm{C} 1-$ MIDR 30N099).

Terrestrial analogs. Wind streaks on Earth can provide insight into wind streak formation. Most wind streaks associated with landforms such as hills, raised-rim craters, and other topographic obstacles can be related to a turbulent wind pattern known as a horseshoe vortex [Greeley et al., 1974]. As shown in Figure 11, wind flow separation and reattachment results in distinctive patterns of sediment erosion and deposition related to the geometry of the landform and the shear stress exerted on the surface by turbulent winds. Wolf Creek impact crater in Australia [McCall, 1965] exemplifies wind erosion and deposition patterns around a raised-rim crater (Figure $2 h$ ); sand deposition occurs in a zone upwind from the rim and as two trailing linear dunes downwind from the crater. The lee zone of the crater lies beneath the merging "cores" of the trailing vortices and is swept free of sand to expose bedrock. This same basic pattern is seen at the Amboy lava field, California [Greeley and Iversen, 1986], where wind flow around a cinder cone creates patterns of sand deposition and sand-free zones; this pattern is visible on both optical and radar images (Figures $2 a$ and $2 b$ ).

Wind streaks of several forms and in a variety of settings on Earth are visible on Seasat and shuttle radar images [Greeley

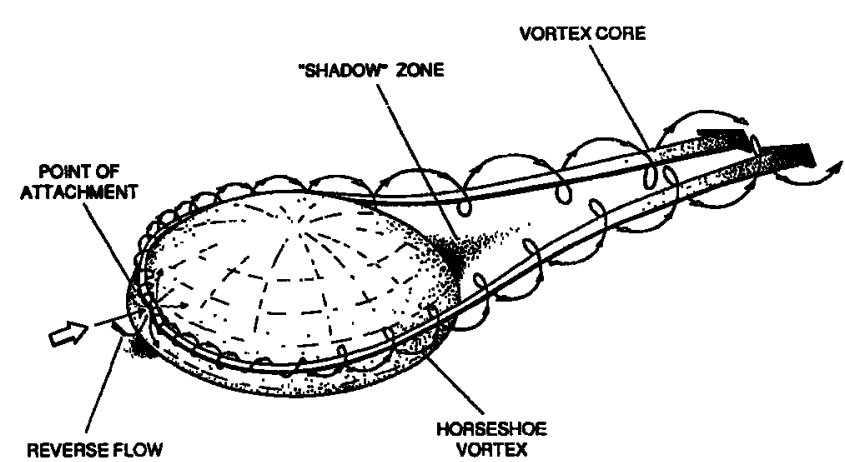

Fig. 11. Diagram of wind flow around topographic obstacle such as a small hill. A "horseshoe vortex" wraps around the hill, creating a zone of turbulence and high surface shear stress in the wake of the hill. Material is preferentially eroded in this zone. Rising turbulent wind components along the outer edges of the vortex cores may cause preferential deposition, creating a "halo" of particulate material around the eroded zone [from Greeley, 1986]. 

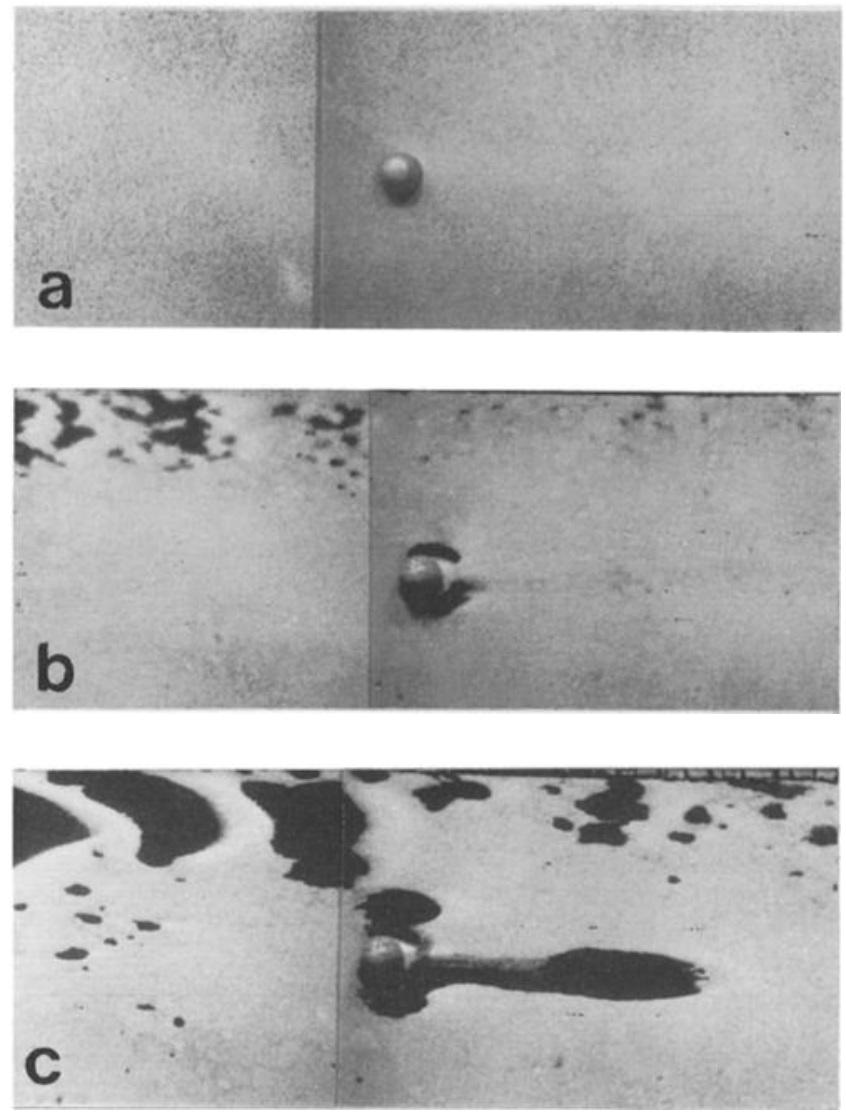

Fig. 12. Venus wind tunnel results for flow over dome-shaped hill; flow is from left to right; area shown is about 30 by 100 cm: (a) before the run, surface was covered with fine quartz sand, (b) during the run, eroded zones show as dark areas where the wind tunnel floor (black) becomes exposed; note the dark erosional "collar" that reflects turbulence associated with the horseshoe vortex shown in Figure 11, and (c) after the run, showing continued erosion and the merging of trailing cores from the horseshoe vortex to form an eroded streak downwind from the hill. By analogy with wind streaks visible on radar images, the areas covered with sand would be relatively radardark, and eroded areas would be radar-bright, assuming that underlying bedrock were rougher than sediment-covered areas.

et al., 1983, 1989; Elachi et al., 1982; Saunders et al., 1990]. In most cases, contrasts in radar backscatter cross section result from deposits of windblown sand (radar-dark) and exposures of bedrock (radar-bright) that form patterns related to the local wind flow field and which are consistent with regional-scale wind regimes.

Wind tunnel simulations. Laboratory experiments also provide clues to the complex flow of winds over and around topographic features and indicate where zones of erosion and deposition occur [Greeley, 1986]. The Venus Wind Tunnel (VWT) was designed to study the physics of particle movement in the Venusian environment and to model erosion and deposition around landforms [Greeley et al., 1984]. To support the analysis of Venusian wind streaks, a series of tests was conducted in which wind flow was assessed over stylized hills. The model hills were placed on the floor of the wind tunnel, the floor was mantled with a $0.5-\mathrm{cm}$ layer of loose sand, and the wind speed was set just above threshold for the sand entrainment $\left(\sim 0.5 \mathrm{~cm} \mathrm{~s}^{-1}\right)$. Runs were continued until most of the sand was removed. Figure 12 shows VWT results before, during, and after one

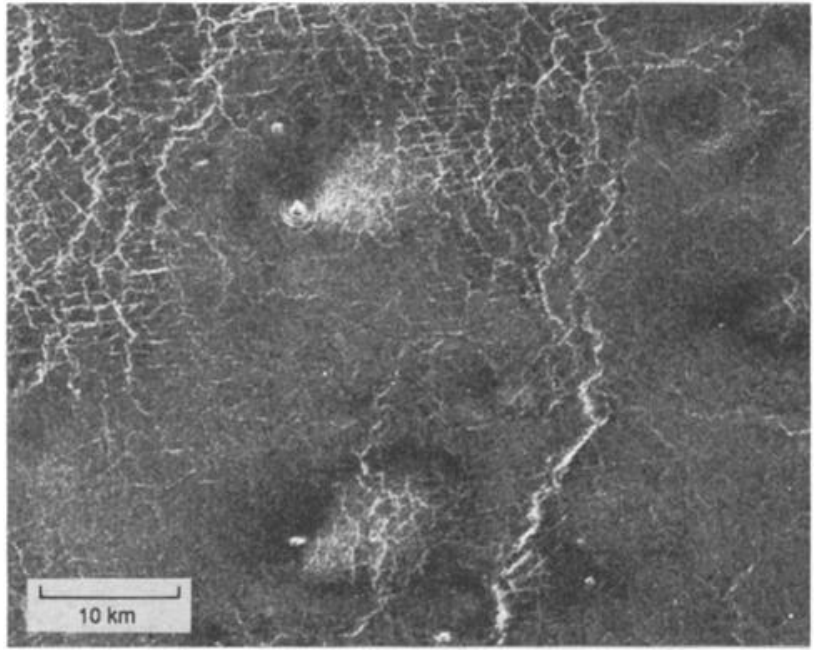

Fig. 13. Radar-bright fan-shaped streaks resulting from erosion. Dark haloes around bright streaks are inferred to be concentrations of particulate material swept from the bright zones by wind. Area shown is centered at $22.3^{\circ} \mathrm{N}, 332.1^{\circ} \mathrm{E}$ and is $\sim 47$ by $60 \mathrm{~km}$ (Magellan F-MIDR 20N334).

run. Patterns of erosion are defined as zones where sand has been removed, exposing the bare (dark) wind tunnel floor. These zones correspond to high wind shear relative to the rest of the floor and are points of flow reattachment as related to the horseshoe vortex flow field (Figure 11).

Summary for Venusian wind streaks. Complexities in the interpretation of backscatter signatures make it difficult to assess the erosional vs. depositional origin of aeolian features on Venus (Table 2). Results from studies of terrestrial analogs and wind tunnel simulations show that erosional zones are expected in the wake of topographic obstacles to the wind as a consequence of flow reattachment and acceleration of the wind. With time, on surfaces mantled with loose sediments, these zones would be scoured free of sediments to expose bare bedrock. In terms of radar-visible streaks on Venus, these zones generally would have brighter radar backscatter cross sections than the surrounding, sediment-mantled terrain, resulting in radar-bright streaks similar to the Amboy streak in the Mojave Desert.

It should be noted that radar bright streaks, as erosional features, are considered to be equivalent to optically dark wind streaks on Mars. For example, the radar-bright fan-shaped streaks shown in Figure 13 are considered to be the result of erosion. The terrain surrounding the streak is relatively smooth and radar-dark, suggesting a mantling deposit, probably part of the parabolic ejecta collar from Aurelia crater. Outside this area, the surface is characterized by a reticulate pattern. We observe that the same reticulate pattem is found within the fan-shaped streak, suggesting that the mantling deposit has been removed by wind erosion enhanced by turbulent flow around the small cone.

Some radar-bright streaks could represent deposits of high reflectivity material. For example, the long, radar-bright streaks originating from small bright hills shown in Figures $14 a$ and $14 b$ could be material eroded from the hills and deposited downwind. Candidate materials are illmenite, pyrite, or other high-density minerals that have high dielectric constants, as suggested by Pettengill et al. [1982, 1983] and Garvin et al. [1985] for some regions on Venus. 


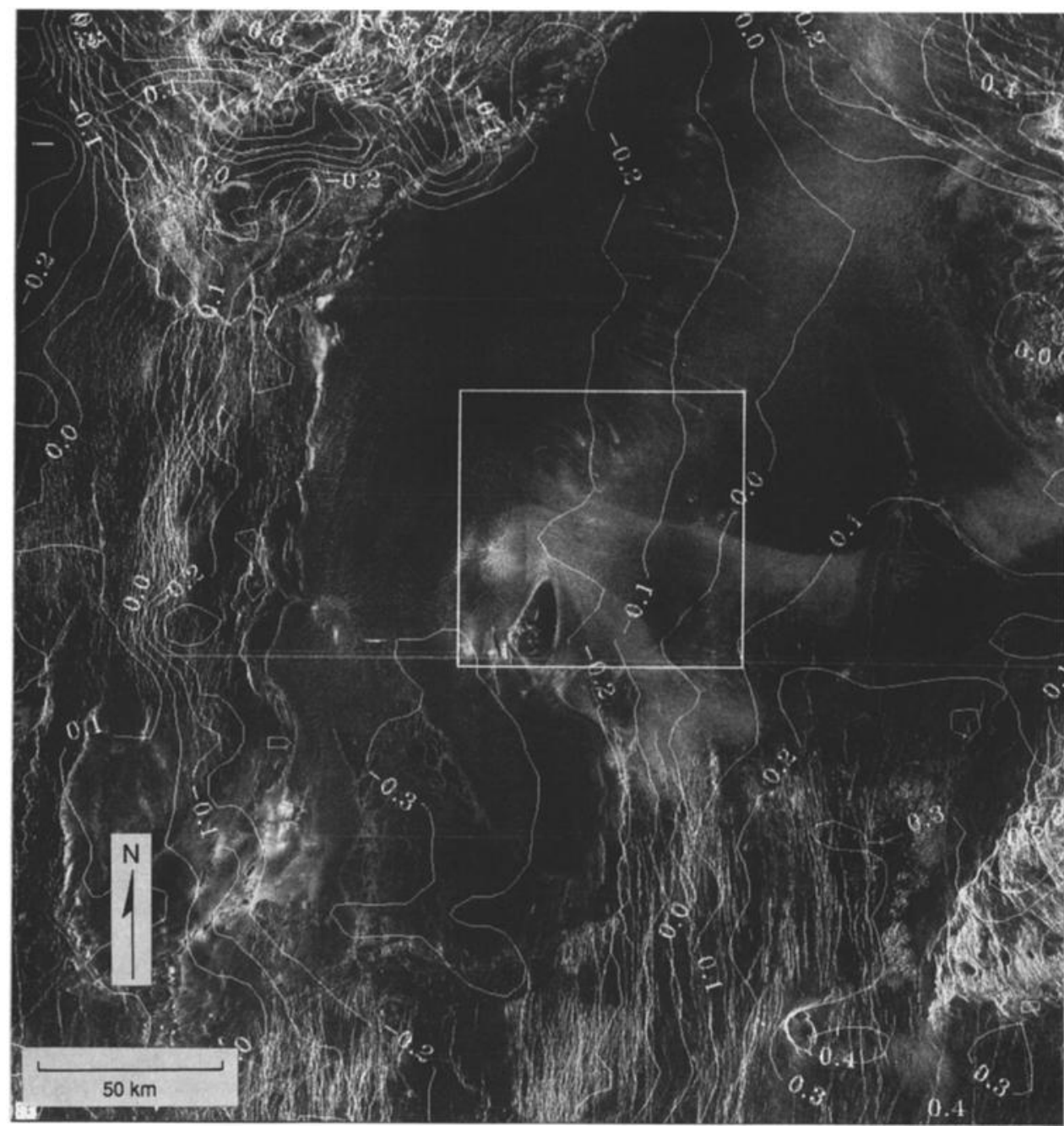

Fig. 14a. The Fortuna-Meshkenet dune field, centered at $67.7^{\circ} \mathrm{N}, 90.5^{\circ} \mathrm{E}$; area shown is 307 by $307 \mathrm{~km}$ (Magellan MRPS 39824).

Because of their relatively high density, they may form "lag" deposits from which lower-density particles have been removed by the wind. Wind tunnel experiments to simulate Venus show that lag deposits could form under Venusian conditions [Greeley et al., 1991]. Such preferential wind winnowing would be expected on Venus in the wake of the hills seen in Figures $14 a$ and $14 b$, and the hills could also be the source of the radar-reflective material.

Radar-dark streaks are more difficult to explain in terms of wind flow patterns. In general, we consider radar-dark streaks to represent deposits of sediments that have low radar backscatter cross sections. Most radar-dark streaks on Venus are associated with ridges and trenches and thus probably represent places where sediments are concentrated; for example, "gaps" in ridges could funnel windblown material into narrow corridors. Radar-dark streaks on Venus associated with "point" features such as hills could also be explained as deposits of sediments. Although runs have not been made in VWT, previous runs made at $1 \mathrm{~atm}$ under low wind speeds and long durations have resulted in long deposits in the obstacle wake (Figure 15). Under these conditions, a "shadow zone" protected from the wind extended far downwind, whereas the entire surface of the model was eroded of loose sediments. Such features produced in the wind tunnel are considered to be analogous principally to the radardark linear streaks seen on Venus (Figure $5 g$ ).

\section{DUNES}

Two possible dune fields have been identified on Venus, one centered at $25^{\circ} \mathrm{S}, 340^{\circ} \mathrm{E}$ and the other centered at $67^{\circ} \mathrm{N}$, $90^{\circ} \mathrm{E}$. Bright wind streaks are associated with both dune fields and indicate that the dunes are oriented transverse to the prevailing winds. The first dune field, initially described by Arvidson et al. [1991], is about $100 \mathrm{~km}$ north of the impact crater Aglaonice and covers an area of $\sim 1290 \mathrm{~km}^{2}$. We designate this the Aglaonice dune field (Figure 16). The Aglaonice dunes range in length from 0.5 to $5 \mathrm{~km}$; however, because the dunes are dominated by specular returns on the radar images, their spacing cannot be determined accurately. The orientation of the dunes and nearby wind streaks suggest winds toward the west.

Dunes on Earth result from the accumulation of saltating particles; as discussed by Bagnold [1941], "sand" size grains ( 60 to $2000 \mu \mathrm{m}$ in diameter) are commonly transported by the wind in saltation. Smaller (i.e., "dust") grains are moved predominantly in suspension, and larger grains (i.e. granules and gravels) move in "creep." Despite the difference in atmospheric density between Earth and Venus, approximately the same mode of transport by size distribution occurs [Iversen and White, 1982]. Consequently, one would expect the dunes on Venus also to be composed of "sand" size material, i.e., grains moved in saltation. 


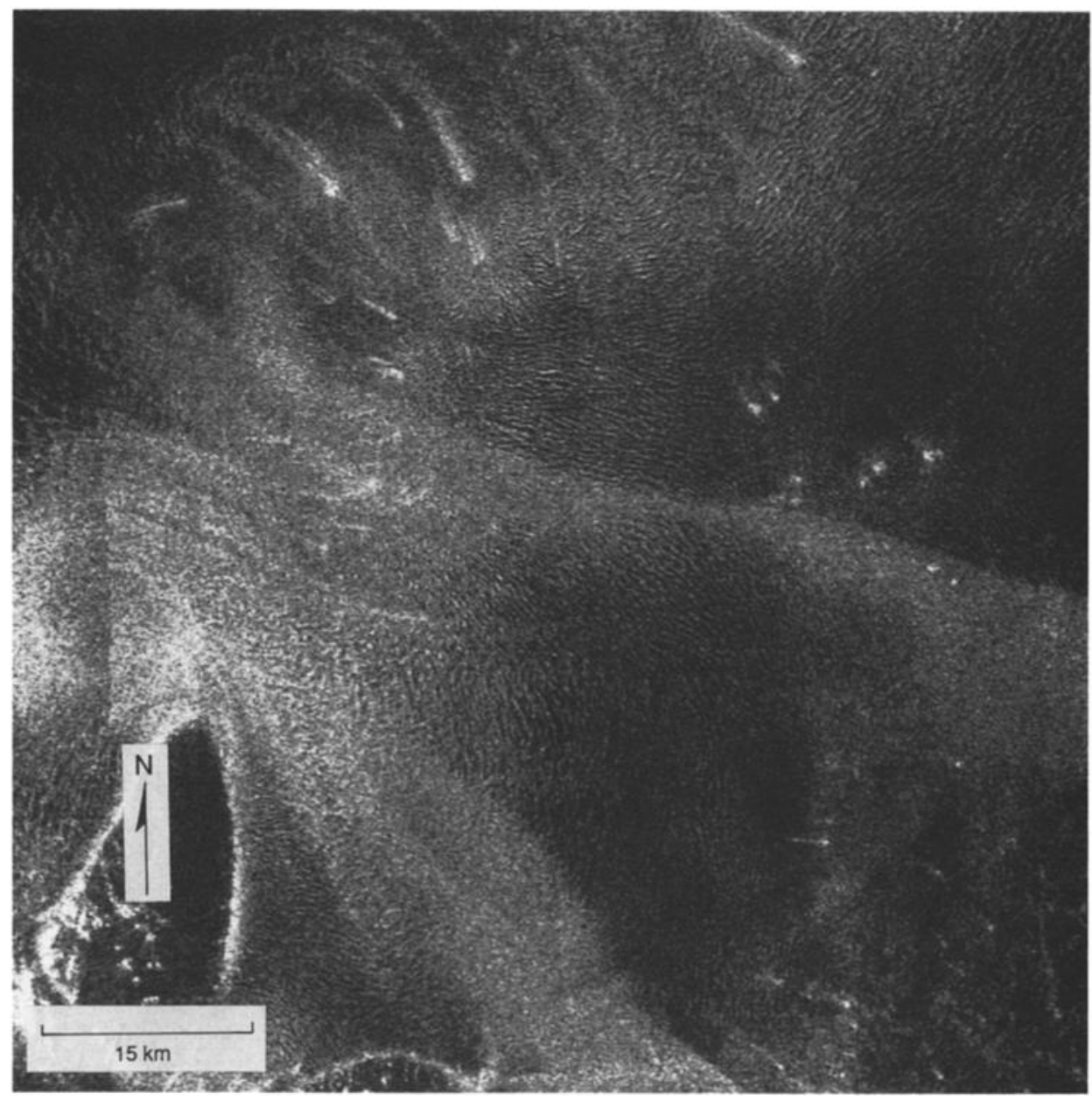

Fig. 14b. Enlargement of area indicated in Figure 14a, showing dunes and radar-bright streaks.

The Aglaonice dune field is in the so-called "crater-farm", an area of relatively abundant impact craters. Consequently, the surface in this area is expected to be a source of sand-sized material from the ejecta generated by the impact event. The dune field is located in an "outflow" deposit extending 250 $\mathrm{km}$ north from Aglaonice. Although the origin of crater outflow features on Venus is unclear, they could result from turbulently emplaced ejecta and/or outflow of lava [Phillips et al., this issue]. Regardless of the process, at Aglaonice, outflow material evidently has been reworked by the wind to form both dunes and wind streaks. Similar aeolian features have not been identified at other outflow deposits thus far in the analyses of Magellan data. The Aglaonice deposit may have been initially less consolidated or may be more weathered than other crater outflow deposits.

The northern dune field (termed Fortuna-Meshkenet) is located in a valley between Ishtar Terra and Meshkenet Tessera. It covers $\sim 17,120 \mathrm{~km}^{2}$ and has $\sim 40$ radar-bright linear wind streaks that occur within the field (Figure 14a). The orientation of the dunes and the wind streaks in the southern part of the field indicate a southeast to northwest wind flow that shifts to a westward flow in the northern part of the field. Two bright streaks near a 12-km-diameter crater north of the dune field also suggest westward wind flow. The dunes range from 0.5 to $10 \mathrm{~km}$ in length, are $-0.2 \mathrm{~km}$ wide, and have an average spacing of $0.5 \mathrm{~km}$. The spacing of the dunes increases toward the western and eastern margins of the valley.

The bright wind streaks in the Fortuna-Meshkenet dune field appear to originate from small $(\sim 200 \mathrm{~m})$, radar-bright cones. The streaks most likely consist of the same high radar reflectivity material as the cones. The sharp brightness boundary in the middle of the image shown in Figure 14a does not appear to be associated with any topographic change, suggesting that the brightness is associated with a change in dielectric constant. Measurements across the boundary show a change in backscatter of $6 \mathrm{~dB}$ (a factor of 4 in returned power) which, in turn, corresponds to a significant change in the dielectric constant. If the lowreflectivity areas are assumed to have a dielectric constant of 2 to 3 , the bright area would have a dielectric constant of 5 to 11. We suggest that the bright area is composed of materials that are of a different composition than the surface on which they occur.

The most likely source for the material forming the Fortuna-Meshkenet dunes is debris from the surrounding regions of complexly deformed tessera. The N-S trending low-lying region between the tesserae appears to have served as a trap for weathered debris. Some material also may be derived from a nearby parabolic halo crater. A similar valley to the east contains no visible aeolian features.

Based upon look angle effects of terrestrial dunes using airborne, Seasat, and shuttle imaging radar images, dunes are bright in low look angle radar images because of quasispecular reflections from smooth dune faces that are nearnormal to the radar beam, where the incidence angle at the dune face is zero [Blom and Elachi, 1981, 1987] as shown in Figure 14c. At Magellan wavelength $(12.6 \mathrm{~cm})$, a radar echo 


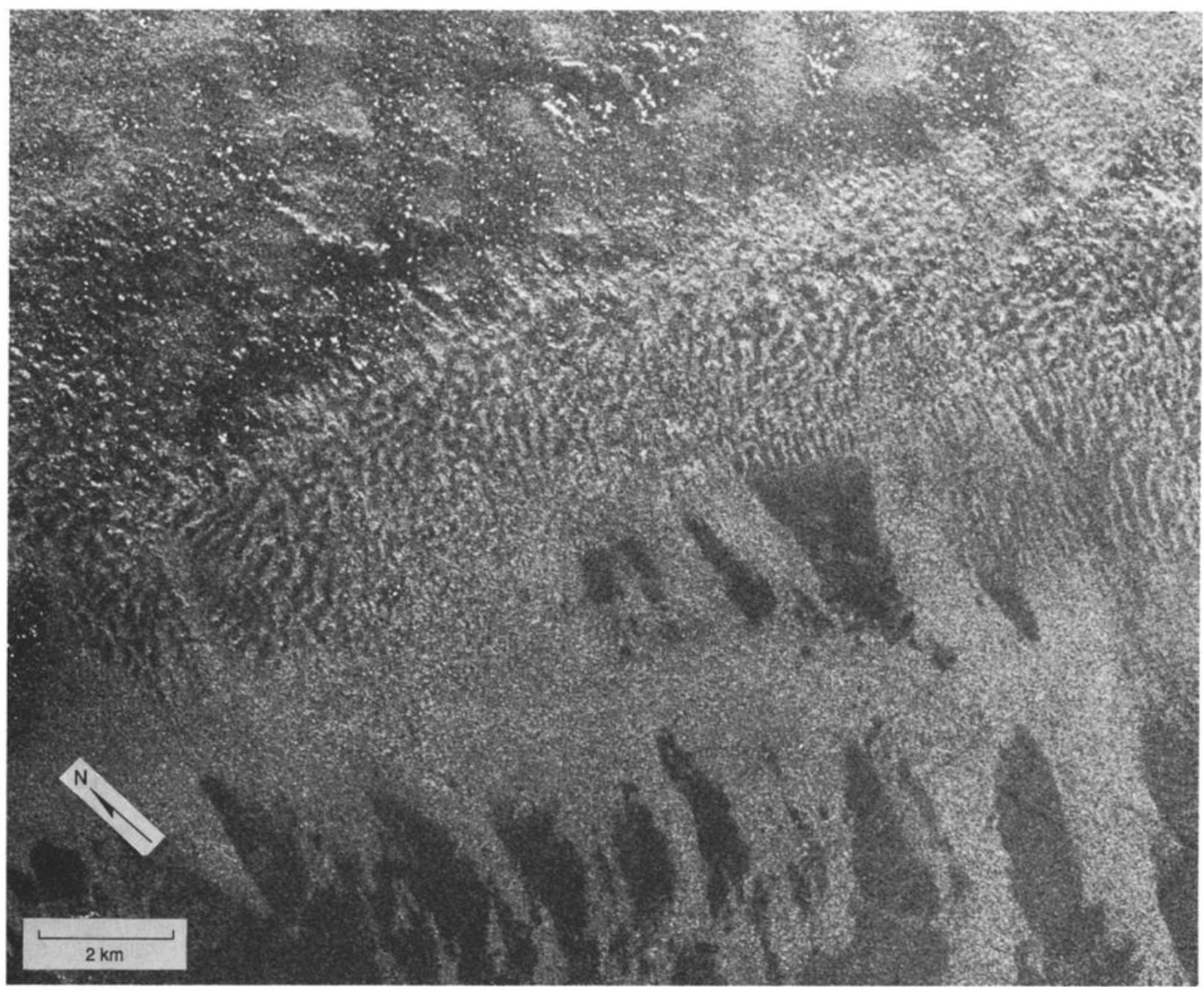

Fig. 14c. Radar image of the dune field in the Gran Desierto, Sonora, Mexico; area shown is $\sim 25 \mathrm{by} 15 \mathrm{~km}$; radar "look direction" is from the southwest (left) toward the northeast (right) (Seasat image revolution 1312).

from a dune is possible only when a sand surface several wavelengths on a side is nearly perpendicular to the imaging radar. Because windblown sand on Earth has an angle of repose of about $33^{\circ}$, radar backscatter from dune slip faces is possible only at look angles less than $33^{\circ}$ where a dune slope is normal to the incident beam [Blom and Elachi, 1987]. Assuming a similar slope geometry for Venusian dunes, only those dunes viewed at look angles $\sim 33^{\circ}$ and with slip faces oriented approximately perpendicular to the radar illumination will yield a radar backscatter on Magellan images. The Aglaonice dune field has an incidence angle of $\sim 34^{\circ}$, and the dune slopes are oriented perpendicular to the radar illumination, thus satisfying the necessary slope geometry for viewing. The Fortuna-Meshkenet dune field was viewed with an incidence angle of $\sim 22^{\circ}$, and most, although not all, of the dunes are oriented nearly perpendicular to the radar illumination. But this dune field also has faces oriented parallel to the radar illumination. Studies by Blom and Elachi $[1981,1987]$ have shown that dune faces that are not near-normal to the radar illumination will not return a quasispecular reflection to the radar. Instead, the dunes become invisible when not imaged near-normal. This would imply that in order to be interpreted as dunes, other scattering effects must be involved, such as change in the roughness or composition (i.e., dielectric constant) across the dunes or between the dunes themselves. One possibility is that the dunes lie on a rough basement. If this is the case, the rough basement would show as bright on the radar image, whereas the smooth dune faces would appear dark. In this case, the dunes need not be near-normal to the radar illumination. Another possibility is that the dunes have a lower dielectric constant than the surrounding terrain so they appear darker. In either case, the periodic image brightness pattern is consistent with images of sand dunes on Earth.

\section{YARDANGS}

Yardangs are streamlined hills that result from wind erosion of rock and indurated sediments. A field of possible yardangs has been identified on Venus at $9^{\circ} \mathrm{N}, 60.5^{\circ} \mathrm{E}$, about $300 \mathrm{~km}$ southeast of the crater Mead (Figure 17a). The region surrounding Mead contains the highest concentration of windrelated features on Venus identified to date and is discussed in more detail in section 5.1. The yardanglike features on Venus consist of sets of slightly sinuous, parallel ridges and grooves. The features average $25 \mathrm{~km}$ long by $0.5 \mathrm{~km}$ wide, with spacing between the ridges ranging from $0.5 \mathrm{~km}$ to 2 $\mathrm{km}$. Unlike wind streaks, they have well-defined boundaries and do not originate from topographic features, such as hills. The proposed yardangs occur in two sets, each composed of 


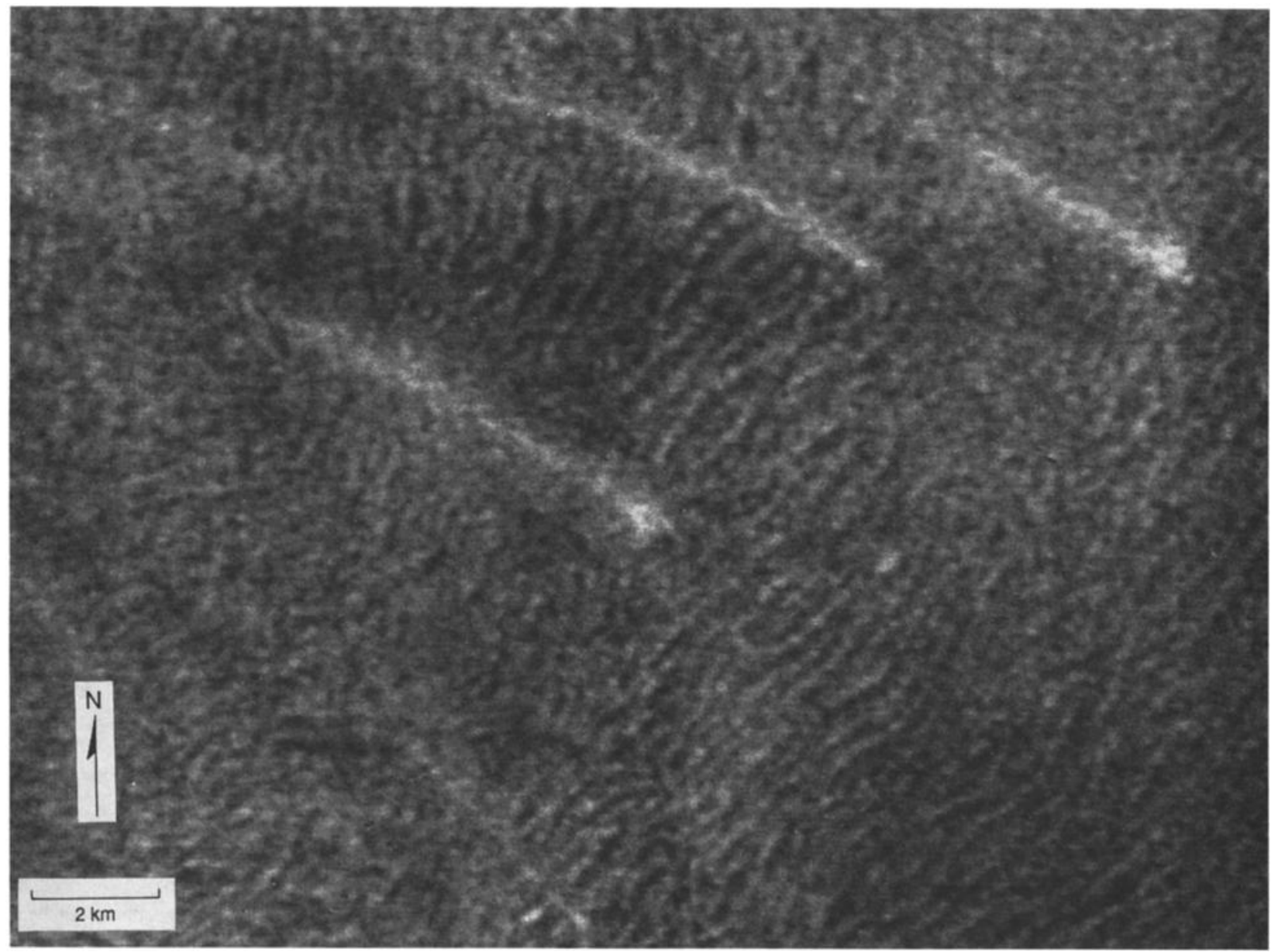

Fig. 14d. Enlargement of some dunes in Figure 14a. The dunes on Earth in Figure $14 c$ and the Venusian dunes shown here are both displayed at the same scale. The image is centered at $67.7^{\circ} \mathrm{N}, 90^{\circ} 5 \mathrm{E}$.

about a hundred individual features. Both sets indicate a northeast-southwest wind regime.

Yardangs occur in many desert regions on Earth and in some areas of Mars (Figure 17b). Yardangs commonly develop on relatively soft deposits that are sufficiently cohesive to retain steep slopes. Lakebed sediments and some volcanic ash deposits are typical materials in which yardangs form [McCauley et al., 1977]. On Earth, yardangs occur in clusters oriented parallel to the prevailing winds which formed them but are also controlled by structural features, such as joints, and erosional patterns such as stream valleys. The shape of yardangs is the result of several factors, including lithology, structure, wind flow field, surrounding topography, and the supply of agents of abrasion [Ward and Greeley, 1984].

The possible yardangs on Venus suggest the presence of relatively friable deposits that have been subjected to erosion and that agents of erosion by the wind have been active in the past or are currently active. The source of the material that formed the possible yardangs is interpreted to originate from the formation of Mead crater. The yardangs indicate that continuing winds in this region have reworked the Mead deposits over time.

\section{Correlations of AeOlian Features With Geology}

The association of wind streaks and other aeolian features with local and regional geology can provide information on the possible sources of windblown material. In general, sand and dust can be produced from impact cratering, volcanic eruptions, and weathering by chemical and physical processes. Mechanical weathering of rock and particle generation on Venus also may occur with the formation of tessera terrain, ridge belts, coronae, and rift zones. Figure 1 shows that the distribution of aeolian features on Venus is not random; rather, they appear to be associated with certain impact craters and some tectonically deformed terrains. To illustrate these associations, we discuss the Mead and Carson crater areas and deformed terrains in Tellus Regio and Ovda.

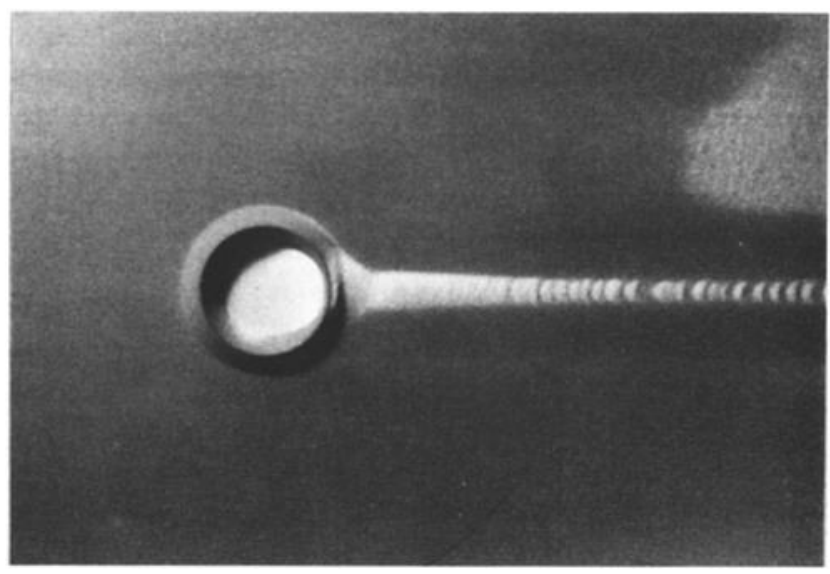

Fig. 15. Wind tunnel results for flow over raised rim crater, generating long depositional feature in wake of crater. 


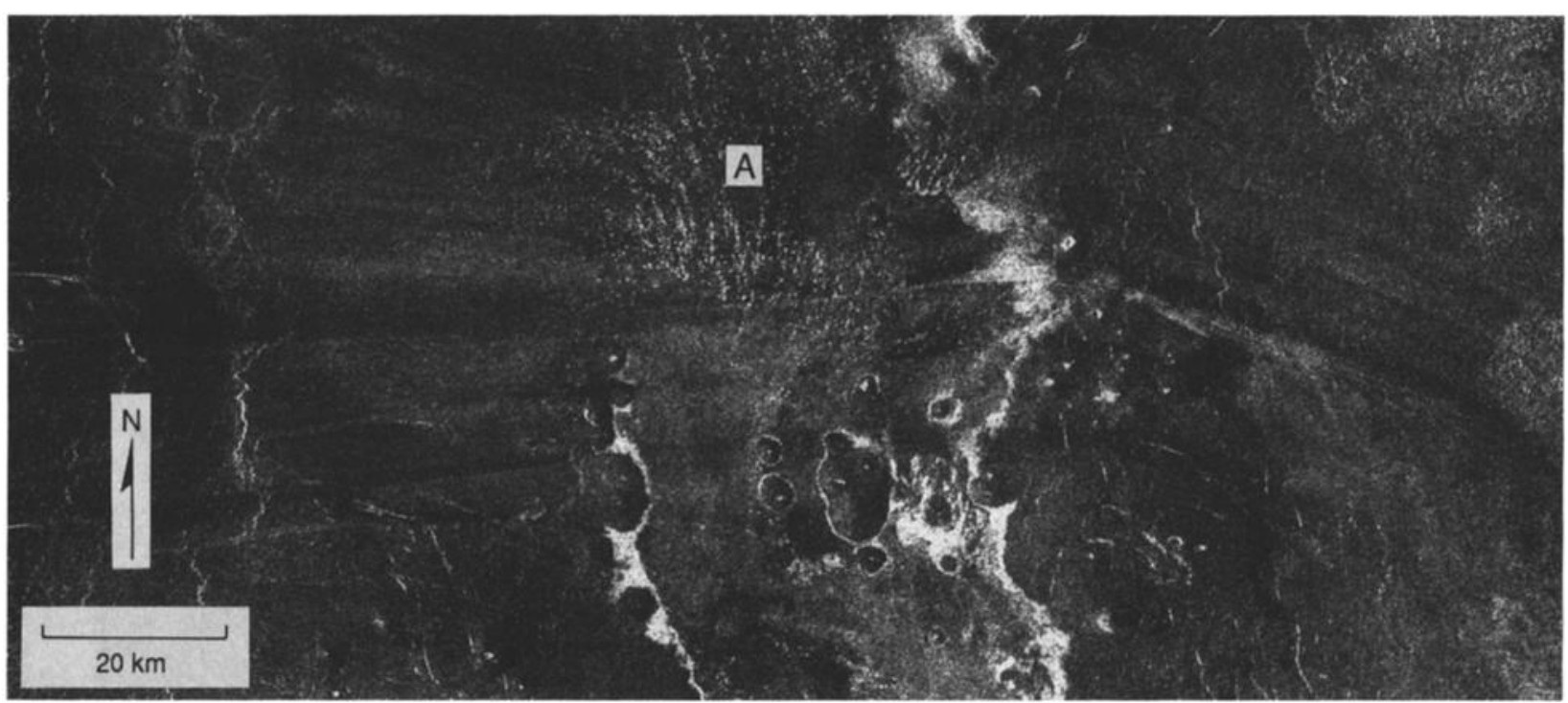

Fig. 16. Aglaonice dune field, centered at $24.8^{\circ} \mathrm{S}$; area shown is $\sim 78$ by $180 \mathrm{~km}$. This dune field, indicated by the specular pattern at "A", is located within an outflow associated with the Aglaonice impact crater. Radar-dark linear streaks sweep across the area, suggesting winds from the east (right) toward the west (left). If this wind orientation is correct, the proposed dunes would be transverse forms (Magellan MRPS 34032).

These regions were chosen on the basis of the abundance and variety of streaks and are unique, rather than typical, regions on Venus. For each area, we have assessed the local geology, possible sources of particulate matter, and the development of the wind streaks.

\subsection{Association of Aeolian Features With Impact Craters}

Mead Crater. Mead (Figure $18 a$ and Plate 1) is $275 \mathrm{~km}$ in diameter and is the largest preserved impact crater found on Venus. It is characterized by two rings, a radar-bright floor, and little apparent ejecta [see Phillips et al., this issue; Schaber et al., this issue]. The area surrounding Mead includes mottled radar-bright and -dark plains and has a large concentration of wind streaks. Most of the streaks in the region are dark linear and dark transverse-ragged forms. A few radar-dark wispy streaks are found west of Mead and about a dozen radar-bright fan-shaped streaks occur northeast and southeast of the crater. Most streaks form in the lee of ridges in the low-lying plains, although some streaks form in the lee of small hills (Figure 18b). Streaks range in length from a few kilometers to $>100 \mathrm{~km}$. Streaks surrounding Mead indicate wind flow toward the equator, at least for the time when the streaks were formed. In addition to the wind streaks, the field of possible yardangs described in section 4 is located southeast of the crater. Immediately east of Mead is a gap in Magellan data caused by superior conjunction. Consequently, the full extent of aeolian features in the area is not known at this time.

The surface around Mead crater appears to be blanketed with fine particles that were probably produced at the time of impact. In addition, the crater is surrounded by a faint radardark halo, visible in the emissivity data (Plate 1). The general area shows lower radar backscatter and emissivity values $(-20.8 \mathrm{~dB}, 0.804$, respectively) than the average $(-15 \mathrm{~dB}, 0.860$, respectively) for the Venusian surface imaged at the same incidence angle ( $45^{\circ}$ in the first mapping cycle). Moreover, some of the lowest emissivity values in the region correspond to concentrations of wind streaks. For example, the radar-dark region associated with the streaks near the center of Figure 18 has an emissivity of 0.808 . In contrast, radar-bright streaks in the area have emissivity values as high as 0.827 . Fresnel reflectivity values (corrected for the effects of diffuse scattering [see Pettengill et al., this issue]) generally have values that are close to the unit complement of emissivity, with a range of values from 0.107 on bright streaks to 0.138 on dark streaks. The overall lower emissivity for the region suggests that if the deposit is fine-grained, then differences in mineralogy may account for the higher dielectric constant.

Carson Crater. Carson (Figure 19a and Plate 2) is one of several impact craters on Venus that is surrounded by a lowbackscatter, low-emissivity parabolic halo [Phillips et al., this issue]. The radar-dark halo is superposed on plains units composed of lobate volcanic flows. Within the halo and in the immediate region (within a 500-km radius of the crater), numerous wind streaks are found that appear to be either a direct result of the impact process or a result of subsequent redistribution of fine-grained materials. The streaks are located in low-lying plains west of Alpha Regio and include radar-bright fan, -dark wispy, and -dark linear forms. Streaks range in length from tens of kilometers to $>100 \mathrm{~km}$. Many of the streaks form in the lee of small cones, although some streaks form in association with ridges. Most streaks indicate winds flowing toward the equator, although others indicate flow in random directions.

Emissivity values on the parbolic halo range from 0.778 to 0.830 , compared with an average value of 0.844 for the surrounding terrain. Values of $\sigma_{0}$, emissivity, reflectivity, and rms slope for some streaks in the Carson area are included in Table 3. As in the Mead region, the dark streaks show higher reflectivities than the bright streaks and the surrounding plains. Emissivity values appear to be strongly influenced by the position of the streak relative to the lowemissivity parabolic halo.

Although Mead and Carson are unusual in their high concentration of aeolian features, wind streaks on Venus are most commonly found near impact craters. Most streaks around craters form within 5 to 6 crater diameters of a crater or crater cluster, indicating that impact-produced particulate material may be locally significant. However, the amount of 


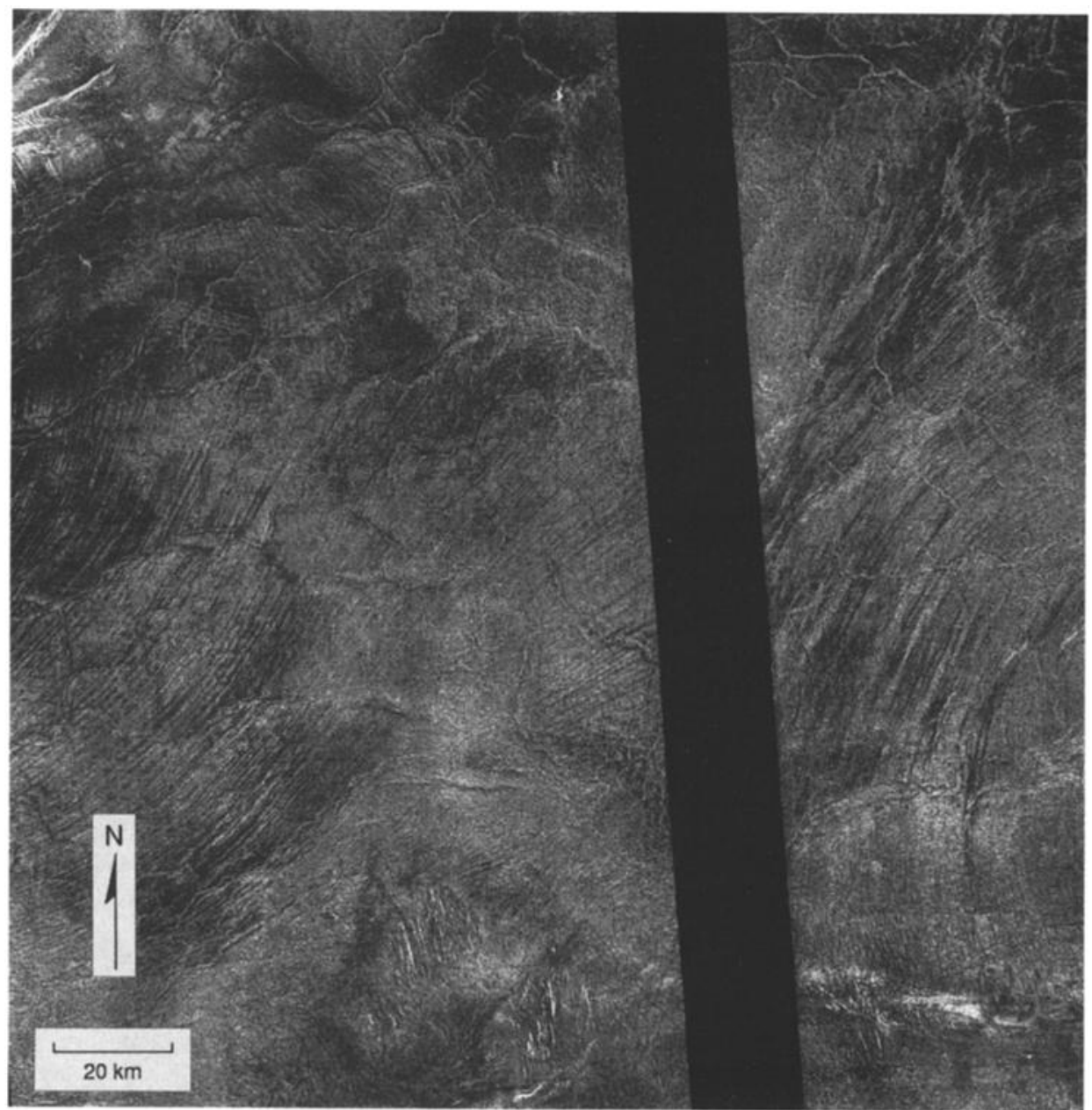

Fig. 17a. Venus yardangs, centered at $9^{\circ} \mathrm{N}, 60.7^{\circ} \mathrm{E}$; area shown is $\sim 200 \mathrm{~km}$ by $200 \mathrm{~km}$ (Magellan MRPS 37879).

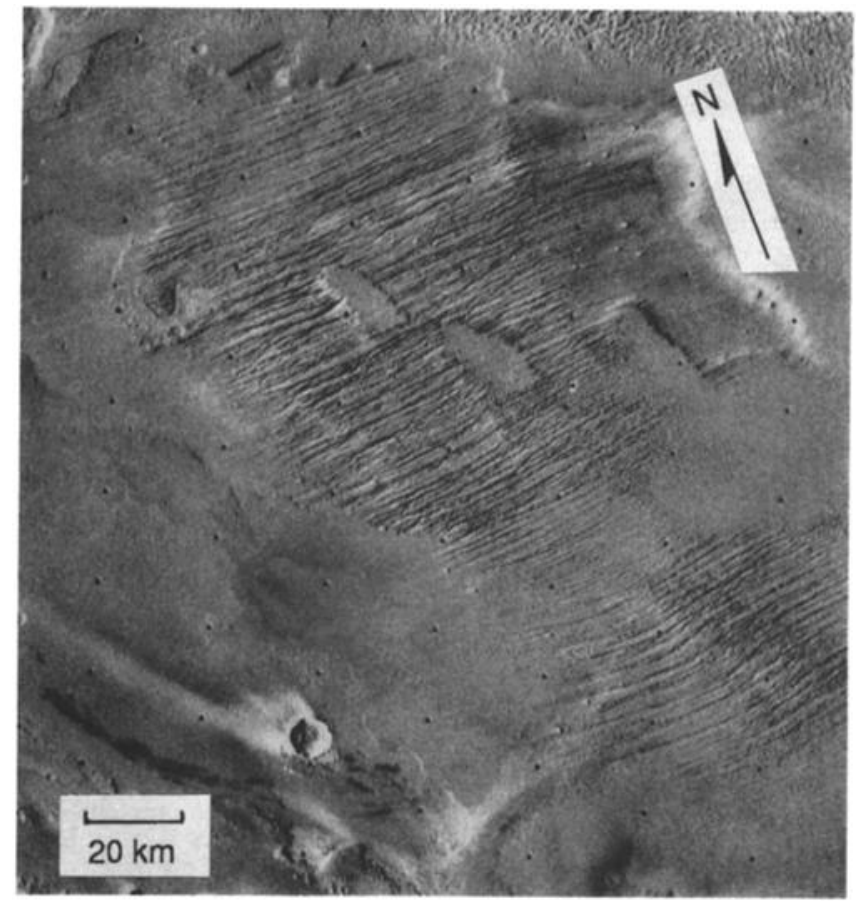

Fig. 17b. Yardangs and mesas in the westem Tharsis region of Mars; area shown is $\sim 190$ by $190 \mathrm{~km}$ (Viking Orbiter frame 44B37). fine material produced by impacts on Venus is not thought to be significant when averaged over the entire globe [Garvin, 1990]. Parabolic halo craters, such as Carson and Mead, most commonly have adjacent streaks, with over $70 \%$ of these craters having associated aeolian features. The occurrence of streaks around impact craters that are surrounded by parabolas or dark haloes and around the diffuse deposits thought to be "failed impacts" [Phillips et al., 1991, this issue] may indicate relatively young regions that have not yet been "homogenized" by the Venus environment. The impact craters where wind streaks are found may represent the youngest craters on the planet, indicating that the streaks may be useful as stratigraphic markers. We interpret the high correlation of streaks with impact craters, and the general lack of streaks in other regions, to indicate that the impact process is the most efficient producer of particulate matter on Venus.

From observations and analyses of aeolian features associated with Mead, Carson, and other large impact craters and from considerations of the properties of the surfaces where aeolian features occur, we suggest the following scenario: Prior to impact, a bow shock was produced in the Venusian atmosphere by the incoming bolide. Because of the high density of the atmosphere, such a bow shock would be capable of producing substantial turbulence where it intercepted the surface and probably was responsible for generating and dislodging weathered debris and injecting sand 


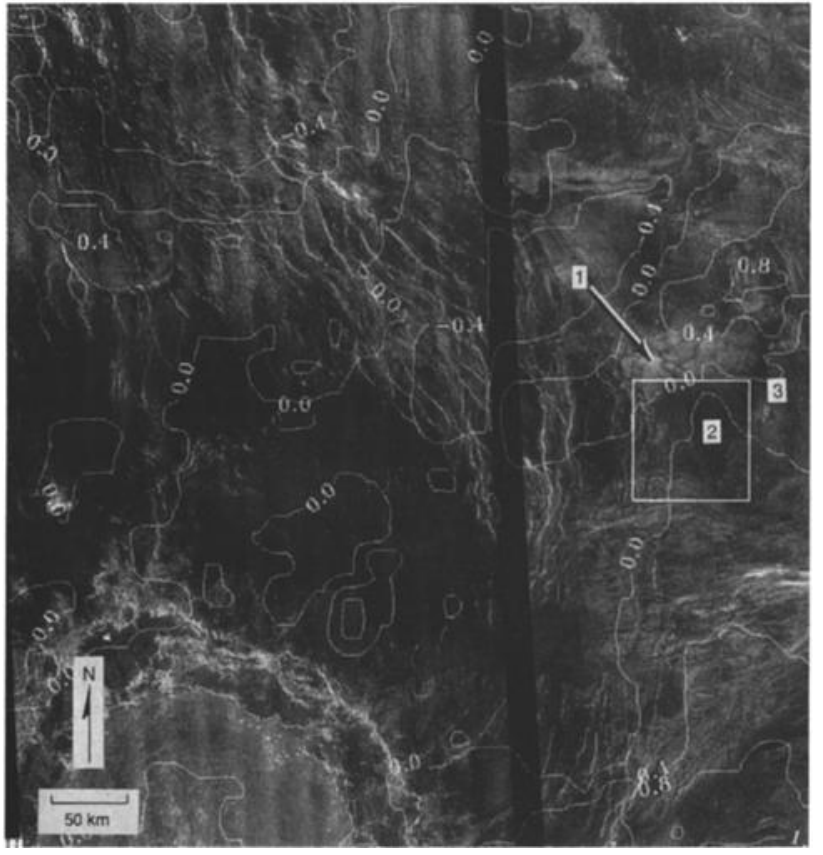

Fig. 18a. Magellan radar image, centered at $15^{\circ} \mathrm{N}, 59.1^{\circ} \mathrm{E}$, of the area northeast of the impact crater Mead (lower left comer of image). Modification of the surface, indicated by wind streaks, extends as much as $150 \mathrm{~km}$ from the crater. White box outlines the location of Figure $18 b$. Numbers on image correspond to Table 3 (Magellan MRPS 39820).

and dust into the atmosphere. Some of the dark patches described by Phillips et al. [1991, this issue] as "failed impacts" could represent particulate material both from the disrupted bolide and from weathered material dislodged locally. Those bolides reaching the surface-generated ejecta of a wide range of particle sizes; together with the material raised by the bow shock, a symmetrical hemisphere of debris expanded from the point of impact. As the mass lofted into the atmosphere, fine particles were caught by the prevailing easterly winds and distributed toward the west to form the radar-dark parabolic collar. Although many wind streaks at Mead crater (and to some degree at Carson) are oriented westward, some are randomly oriented and may reflect local turbulence, or formation at a time not associated with the impact.

\subsection{Association of Aeolian Features With Tectonically Deformed Areas}

Wind streaks and other aeolian features are found in some areas that have been tectonically deformed. For example, the area southwest of Tellus Regio, shown in Figure 20, contains abundant wind streaks that do not appear to be related to an impact crater (the nearest impact crater, Voynich, is $>1000 \mathrm{~km}$ away). Consequently, the particulate material associated with the wind streaks was probably generated from the complexly deformed, rugged terrain of Tellus Regio. The streaks in this region include radar-dark linear streaks and radar-bright and -dark fan-shaped streaks. Wind streaks range from $\sim 10$ to $>50 \mathrm{~km}$ in length. All of the streaks are in low-lying plains immediately adjacent to a zone of complexly deformed terrain that extends from the main body of the highlands. Streaks in this region tend to form in the lee of ridges in the plains, with some dark material apparently accumulating behind topographic

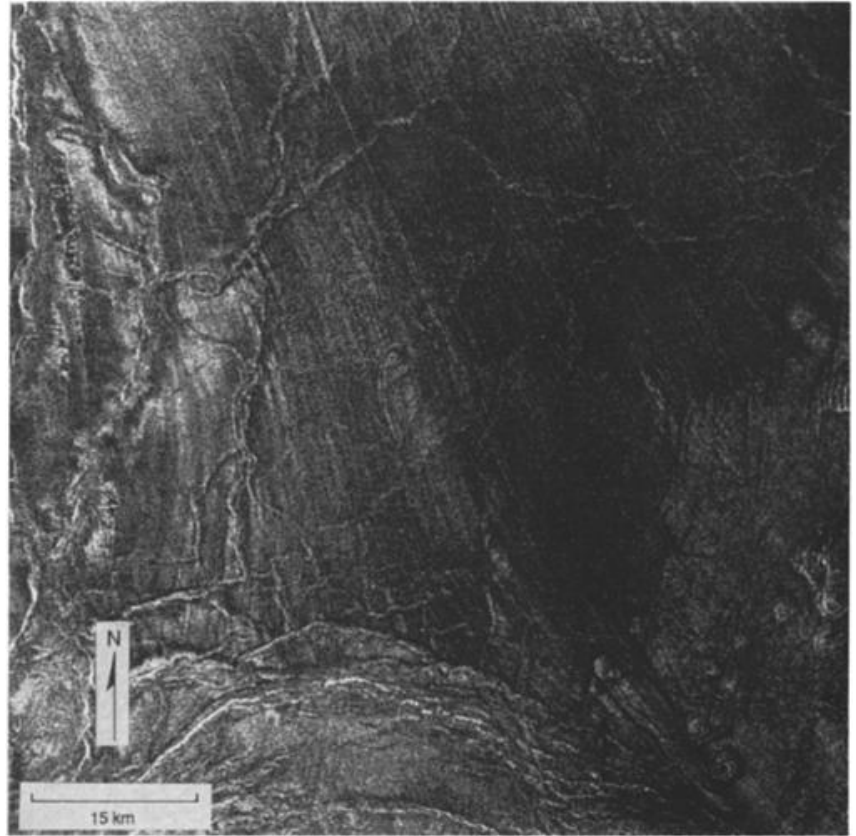

Fig. 18b. Detail of linear streaks northeast of Mead. Interfingering bright and dark streaks complicate the interpretation of depositional versus erosional origins; area shown is centered at $15^{\circ} \mathrm{N}, 60.4^{\circ} \mathrm{E}$ (Magellan MRPS 39821).

obstacles. The radar properties of the streaks (Table 3) indicate that the bright streaks have higher radar backscatter cross sections than the surrounding plains, whereas the dark streaks have lower backscatter cross sections than the surrounding plains. In addition, the darkest streak areas show emissivity values $\sim 0.02$ lower than the surroundings, suggesting slightly higher diclectric constants for the less dark streaks. The appearance of both the bright and dark areas in the SAR is therefore probably a result of roughness differences, rather than differences in dielectric constant. In this region, the dark and bright streaks behind the ridges are interpreted to represent adjacent areas of deposition (dark streaks) and scour (bright streaks).

Hestia-Rupes/Ovda Regio is also tectonically deformed and has a concentration of streaks (Figure 21). Wind strcaks extend uphill from tessera blocks, indicating upslope winds. As detailed by Arvidson et al. [this issue], the streaks delineate an elevation contour boundary in which strcaks occur west of the boundary at lower elevations. To the east (at higher elevations) the plains have enhanced backscatter cross sections, and as discussed by Arvidson et al. [1991], this variation may be related to elevation-dependent weathering reactions. Above a critical elevation $(6054 \mathrm{~km}$ [Pettengill et al., 1983]) the plains are inferred to be bright because of the presence of high dielectric materials which may be stable at the lower temperatures and pressures found at higher elevations. The streaks developed because winds segregated these matcrials within the elevation zone where the weathering reaction occurs.

Wind streaks are also associatcd with a few other tectonically deformed regions, such as Alpha and Laima tesserae and in some ridge belt regions. Tesscrae and ridge belts have been fractured and uplifted, resulting in mechanical erosion that may have produced sufficient fine-grained material to form acolian features. On the other hand, no 


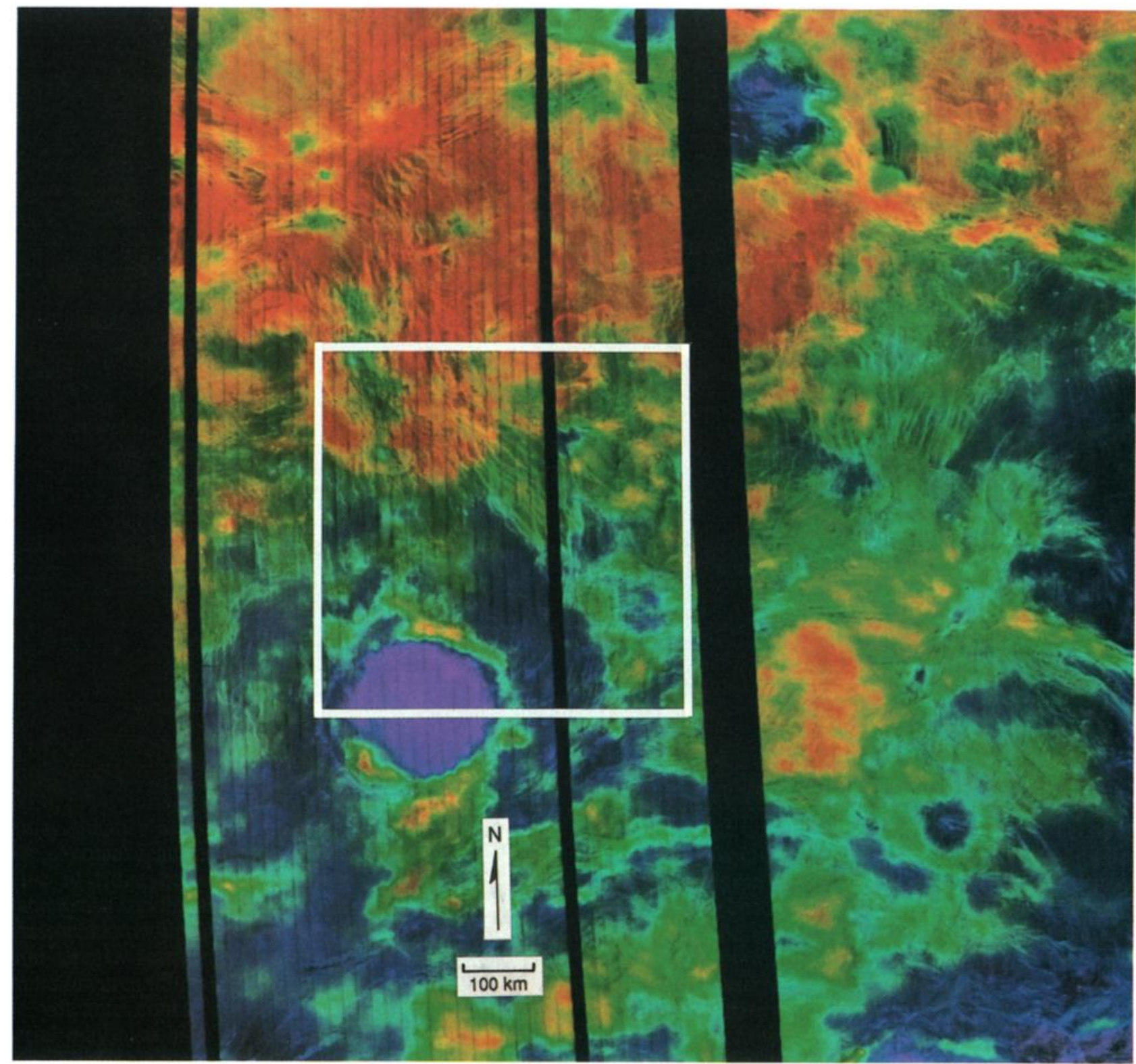

Plate 1. Image data with emissivity values shown in color overlay in the vicinity of Mead crater (circular purple area in upper right). Emissivity values in the central part of Mead are as low as 0.702 , while a large region around the crater has a mean emissivity of 0.804 , which is roughly 0.05 less than a typical plains surface. Values $\leq 0.788$ are shown as violet; $\geq 0.840$ are shown as red.

acolian features have been identificd around coronae and rift zones, both of which are characterized by extensive tectonic deformation. However, both rift zones and coronae are far less complexly deformed than tesserae and, thus, may not produce sufficient sediment to form acolian features. In addition, these terrains lack the steep outer slopes of tesserac that may enhance mass wasting and the generation of local winds. Aeolian features may be more commonly located in the lee of ridge belts due to their unique topographic characteristics serving as an obstacle to the wind, rather than their association with significant mechanical erosion.

Wind streaks form least frequently in association with volcanic features. Streaks, however, do form in the wake of some volcanic cones, but in many cases the particulate material may also have been derived from nearby impact craters. Explosive eruptions on Venus are thought to require large amounts of volatiles, and may be relatively rare [Garvin et al., 1982; Head and Wilson, 1986]. Alternatively, volcanic particulate matter may be easily welded and thus more difficult to rework with the wind.

On most planets, more particulate matter is generated with age as surface features weather and erode. In general, a relatively large amount of particulate matter on Venus seems to indicate a younger age, as in the case of the parabolic halo craters. Arvidson et al. [this issue] have observed that lava flows tend to become more "homogenized" over time. This process may be related to some material binding process on the surface. For example, laboratory experiments show that in the high-temperature, high-pressure environment of Venus, particulate material tends to "cold weld" and becomes more difficult to move by the wind [Marshall et al., 1991]. Therefore, recent impacts (i.e., Carson), regions of ongoing 
tectonic activity (i.e., Tellus), or elevated regions with unique weathering characteristics (i.e., Ovda) may be some of the relatively few sites on the planet where loose material is present and is moved by the wind.

\section{CONSTRANTS ON MODELS OF ATMOSPHERIC CIRCULATION}

As discussed in section 1, atmospheric circulation near the surface of Venus could be predominantly: (1) a Hadley cell with equatorward surface winds, (2) an anti-Halley cell with surface winds away from the subsolar region, (3) a zonal circulation with westward surface winds, or (4) something more complex. The global pattern of wind streak azimuths may provide clues as to which of these models (if any) characterize the near-surface circulation.

Figure 9 shows that many streaks are oriented with equatorward components. This is particularly evident in the southward orientations of streaks in the northem hemisphere regions at $\left(25^{\circ} \mathrm{N}, 335^{\circ} \mathrm{E}\right),\left(10^{\circ} \mathrm{N}, 65^{\circ} \mathrm{E}\right)$, and $\left(20^{\circ} \mathrm{N} 100^{\circ} \mathrm{E}\right)$ and in the northward orientations of streaks in the southern hemisphere at $20^{\circ} \mathrm{S}, 345^{\circ} \mathrm{E}$. Northem hemisphere streak azimuths are clearly concentrated around $180^{\circ} \mathrm{E} ; 73 \%$ of the total population of northern hemisphere streaks have azimuths between $90^{\circ}$ and $270^{\circ}$. Similarly, $77 \%$ of the southern hemisphere streaks have azimuths between $0^{\circ}$ and $90^{\circ} \mathrm{E}$ and $270^{\circ}$ and $360^{\circ} \mathrm{E}$. Northern hemisphere streaks are predominantly oriented southward whereas southern hemisphere streaks are mainly oriented northward.

The streak orientations are consistent with a near-surface Hadley cell circulation, and accordingly, they provide observational support for the existence of such an atmospheric circulation pattern. This conclusion is preliminary and should be treated circumspectly until more complete wind streak data for the whole planet are obtained and analyzed. Possible observational biases, such as those associated with imaging geometry, need to be assessed more carefully. For example, the orientation of Magellan spacecraft ground tracks might result in preferential radar detection of streaks which lie parallel to them.

The latitudinal distribution of wind streaks may contain information on the strength of the equatorward near surface winds in the Hadley cell or on the poleward extent of the Hadley circulation. There is a strong concentration of wind streaks in the southern hemisphere between $17^{\circ}$ and $36^{\circ} \mathrm{S}$ latitude (Figure 7). Wind streaks are more uniformly distributed with latitude in the northern hemisphere, although there is a concentration of streaks between $23^{\circ}$ and $30^{\circ} \mathrm{N}$ latitude (Figure 7). The area between $17^{\circ} \mathrm{S}$ and $36^{\circ} \mathrm{S}$ is $30 \%$ of the area of the southern hemisphere, but $57 \%$ of the southern hemisphere wind streaks are concentrated there. Similarly, the area between $23^{\circ} \mathrm{N}$ and $30^{\circ} \mathrm{N}, 10 \%$ of the northern hemisphere area, contains $20 \%$ of northern hemisphere wind streaks. The peaks in the latitudinal distribution of wind streaks between $23^{\circ} \mathrm{S}$ and $30^{\circ} \mathrm{S}$ and $23^{\circ} \mathrm{N}$ and $30^{\circ} \mathrm{N}$ tend to suggest that equatorward Hadley circulation winds are strongest at these latitudes. The broad distribution of northern hemisphere streaks over all latitudes (Figure 7) suggest that the Hadley cell in the northern hemisphere may extend all the way to the pole; however, the relatively small number of streaks in the southern hemisphere poleward of

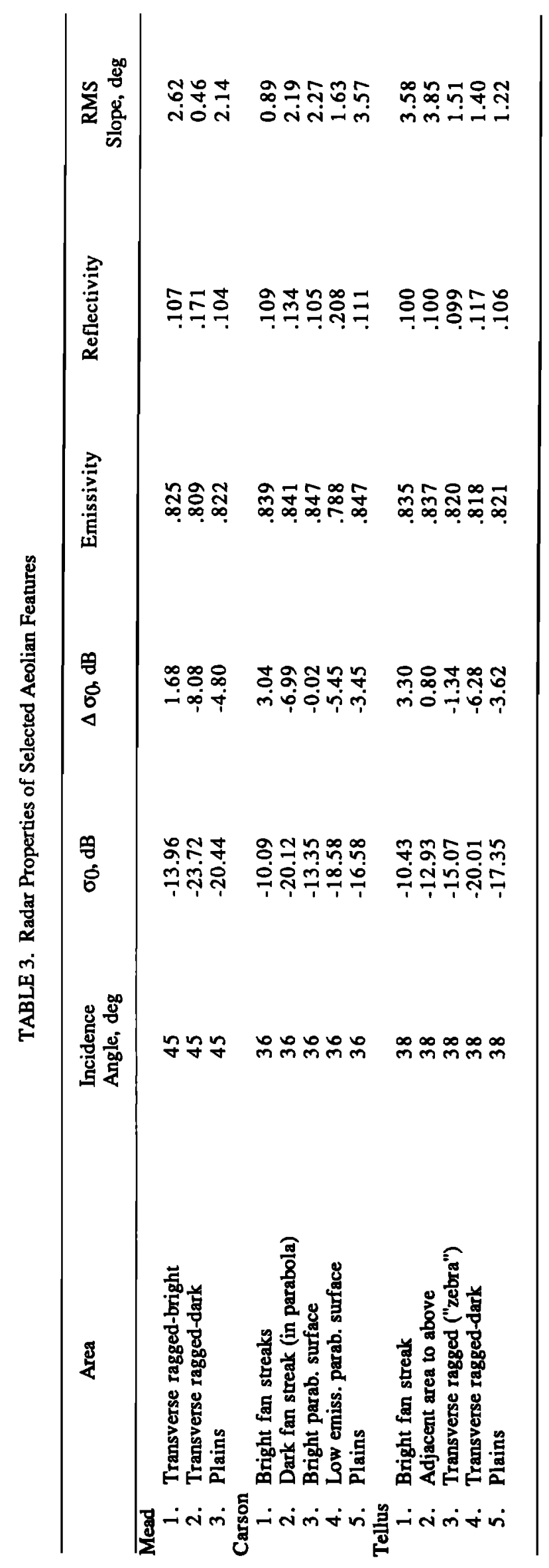




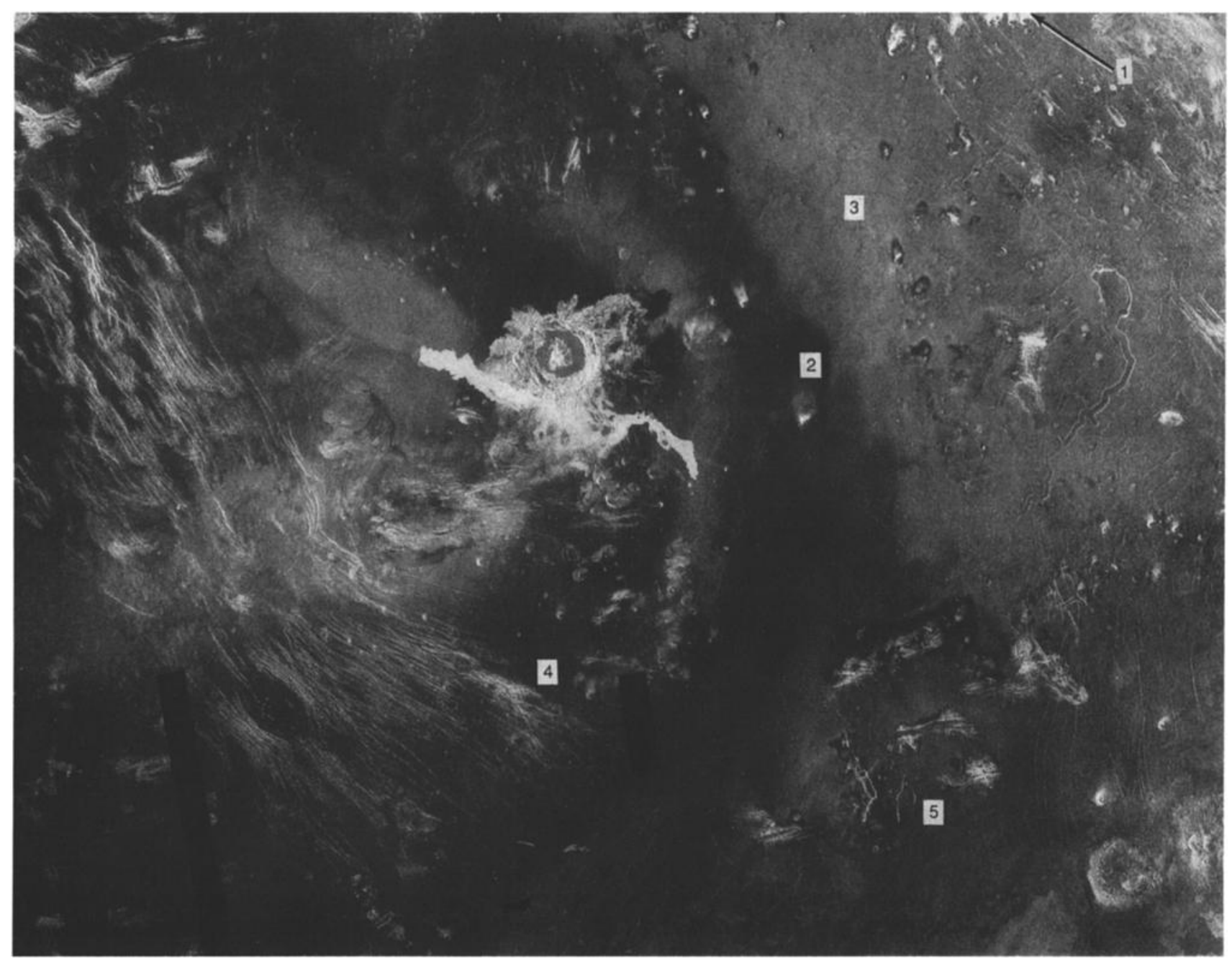

Fig. 19a. Magellan radar image of the area around the impact crater Carson, centered at $25^{\circ} \mathrm{S}, 345^{\circ} \mathrm{E}$, radar-dark halo associated with the cluster of craters, and the parabolic-shaped "collar" associated with Carson. Numbers on image correspond to Table 3 (Magellan F-MIDR 25S345).

$36^{\circ} \mathrm{S}$ implies weaker winds or less poleward penetration of the southern hemisphere Hadley cell. There is some sampling bias, however, because Magellan coverage is incomplete over the southern latitudes and south polar area. The implications of Figure 7 for atmospheric circulation must be viewed with caution at this stage of our analysis because the latitudinal distribution of wind streaks can also be influenced by other factors that would vary with latitude such as the supply of windblown material.

Streak orientations show no preferential alignments that would confirm or deny the existence of other lower atmosphere motions such as the anti-Halley circulation or the westward zonal flow discussed earlier. For example, streak azimuths point eastward as frequently as they point westward. Thus, the dominant circulation of the cloud level atmosphere does not penetrate to the surface with sufficient strength to preferentially organize the wind streaks toward the west. The wind vector at a fixed point on the surface rotates through $360^{\circ}$ during the diurnal cycle of the anti-Halley circulation. Accordingly, it is difficult to devise a test of the wind streak data that would provide evidence for or against the anti-Halley cell.

\section{SUMMARY AND CONCLUSIONS}

Wind streaks are the most common aeolian feature on Venus. More than 3400 have been identified in this study. They occur in a variety of shapes and include radar-bright, radar-dark, and mixed radar reflectivity forms in relation to the background on which they occur. Most streaks are found in relatively smooth plains in latitudinal bands of $23^{\circ} \mathrm{S}$ to $30^{\circ} \mathrm{S}$ and $23^{\circ} \mathrm{N}$ to $30^{\circ} \mathrm{N}$. Wind streaks tend to be oriented downwind toward the equator, consistent with surface winds related to a Hadley circulation in the lower atmosphere. Data do not support Halley circulation patterns related to subsolarantisolar heating contrasts, although observations are limited to test this possibility. Wind streaks are found at all elevations on Venus. In contrast to pre-Magellan predictions of downslope winds, most wind streaks are found on gentle slopes $\left(<2^{\circ}\right)$ and are randomly oriented with regard to slope. Locally, as in Ovda Regio, streaks can be oriented upslope.

Both erosional and depositional aeolian features have been identified on Venus. The presence of possible dunes (depositional features) provides clues to the nature of some of the sediments and their behavior in the aeolian environment. 


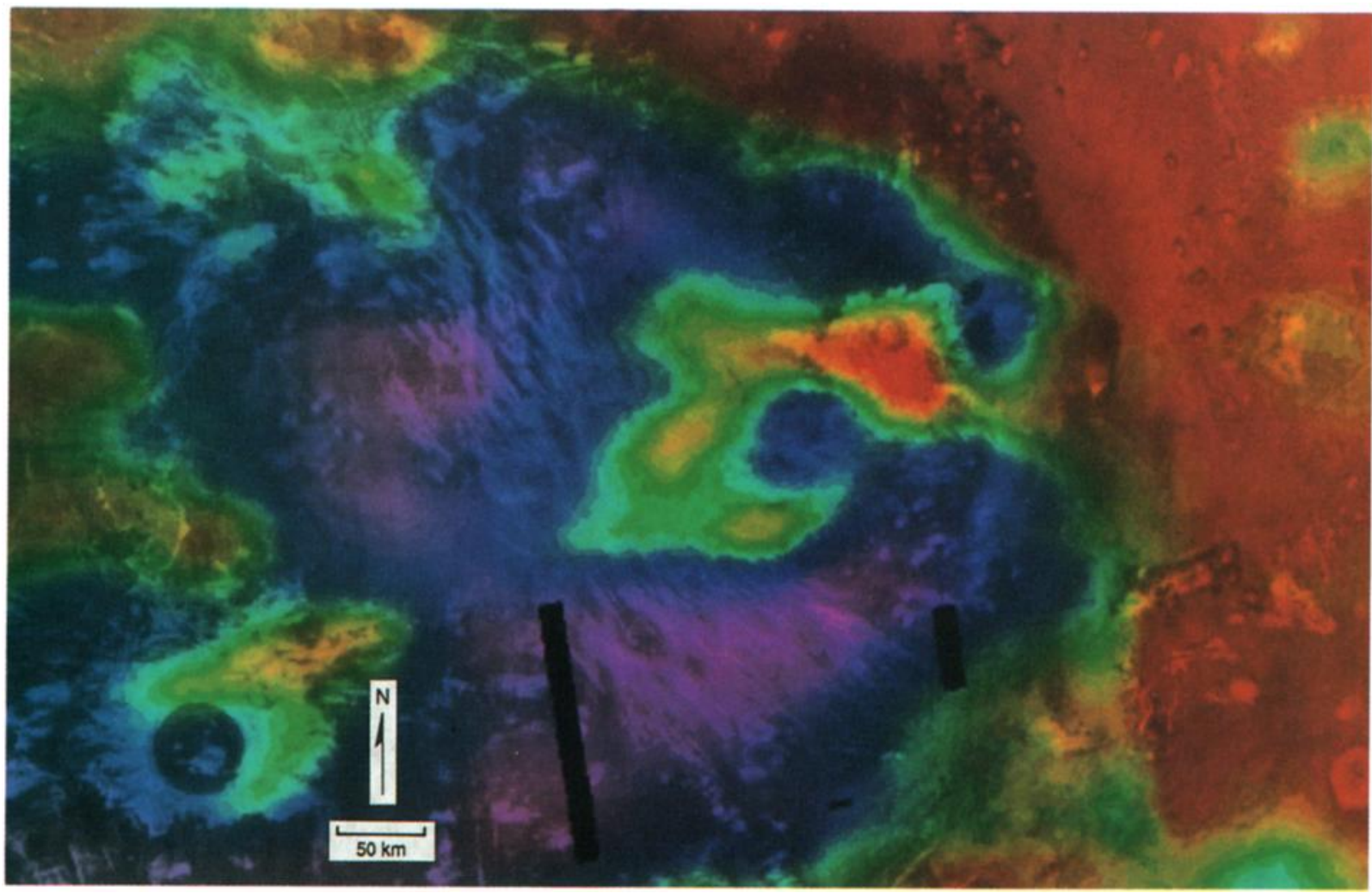

Plate 2. Image data for the same area as above, with emissivity values shown in color overlay. Emissivity values in the vicinity of the craters are typically 0.05 lower than those in the surrounding regions. Values $\leq 0.784$ are shown as violet; $\geq 0.844$ are shown as red.

Sand dunes form only from sand-size particles (60 to 2000 $\mu \mathrm{m}$ in diameter) which are transported primarily in saltation by the wind, regardless of planetary environment [Greeley and Iversen, 1985]. Consequently, if the features identified in Figures 14 and 16 are dunes, they signal the presence of sand grains and processes that produce particulate material. Although the identification of yardangs is tentative, their possible presence also provides insight into the aeolian regime on Venus. As features formed by wind erosion, yardangs show that windblown particles are capable of eroding material despite the relatively low kinetic energy produced by slow-moving winds.

In conclusion, the surface of Venus is characterized by low rates of erosion, primarily due to the lack of water on the surface. Mechanical erosion through tectonic deformation in ridge belts and regions of tessera may produce small amounts of particulate matter that can form aeolian features. Volcanic deposits may also play a small role in producing fine material on Venus: many streaks form in association with cones of probable volcanic origin. However, the primary contribution to the production of particulate matter on Venus is from impact cratering. Aeolian features form predominantly near impact craters, especially those with associated ejecta haloes or parabolas, or near dark deposits thought to be "failed" impacts [Schaber et al., this issue].

Continuing analysis of the backscatter cross sections of aeolian features will provide further insight into erosional and

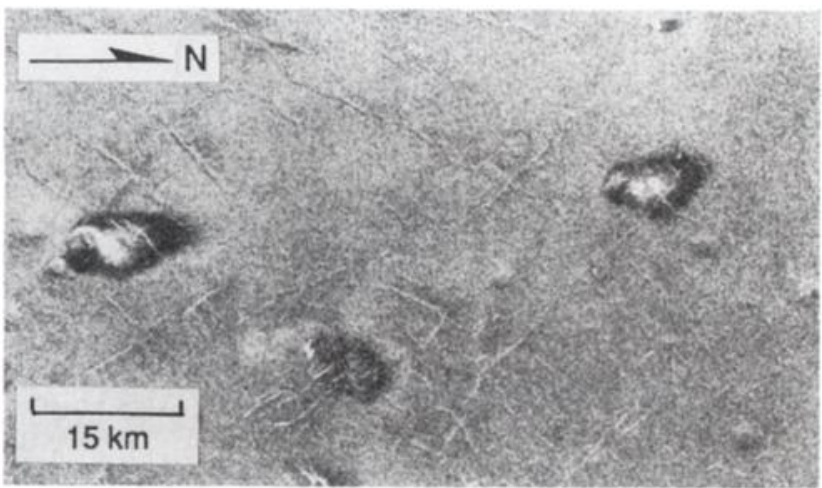

Fig. 19b. Detail of streaks northeast of Carson. Note variation in backscatter from the core to the edge of the streaks.

depositional processes on Venus. Data from Magellan's extended mission will be used to assess the backscatter characteristics of aeolian features of different viewing geometries and to obtain a complete inventory of wind-related features on Venus. Most significantly, over the next several years, Magellan will provide the opportunity to detect changes in aeolian features or the formation of new features, providing further information on atmosphere/surface interactions and the nature and evolution of surface materials on Venus. 

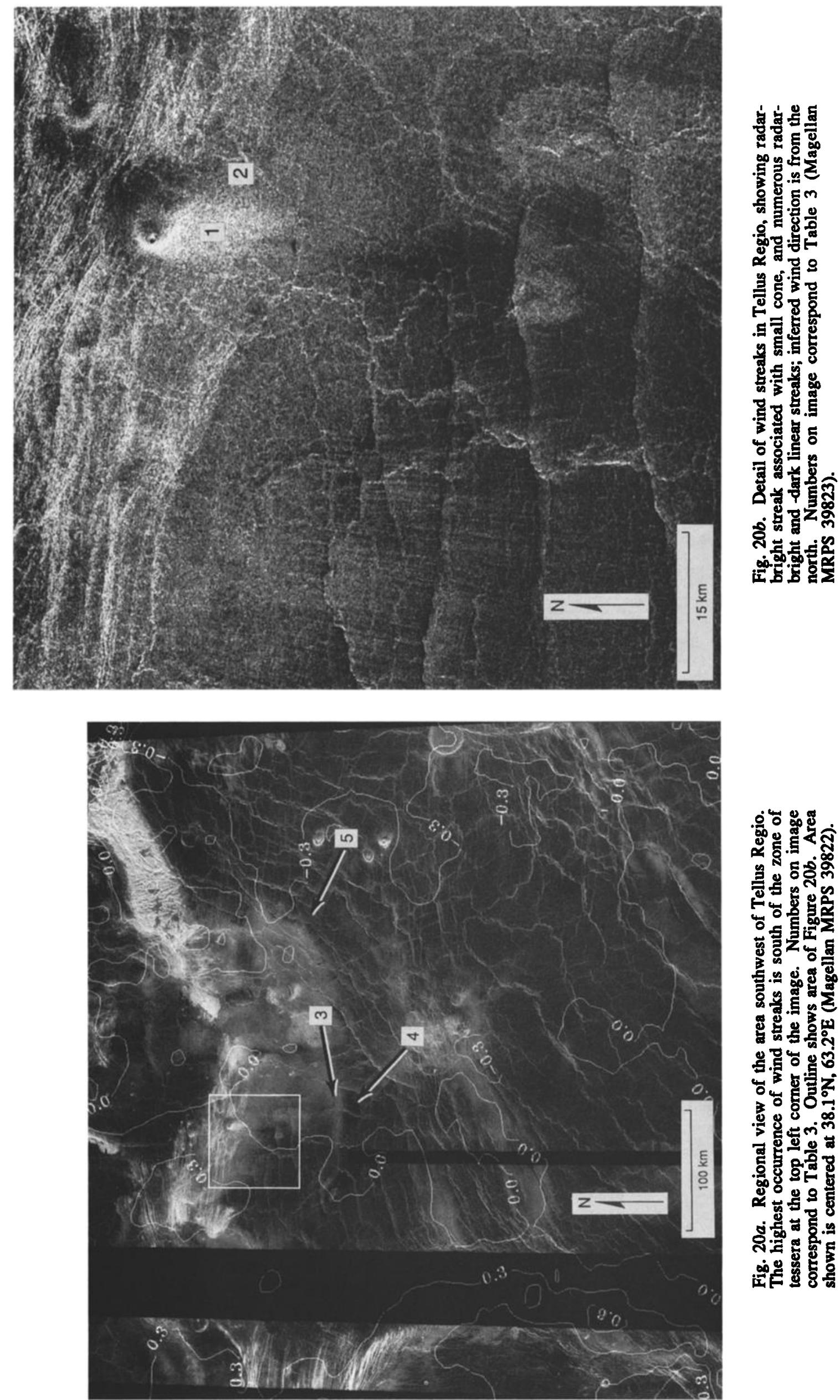

ㅎํ용

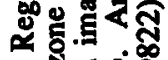
ㅎํ욜 동 o을 要官之至 . 열 5

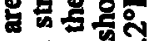
ธक्ड़ 냉형 o 匏m 당 응

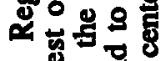
में 줄 동

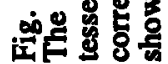



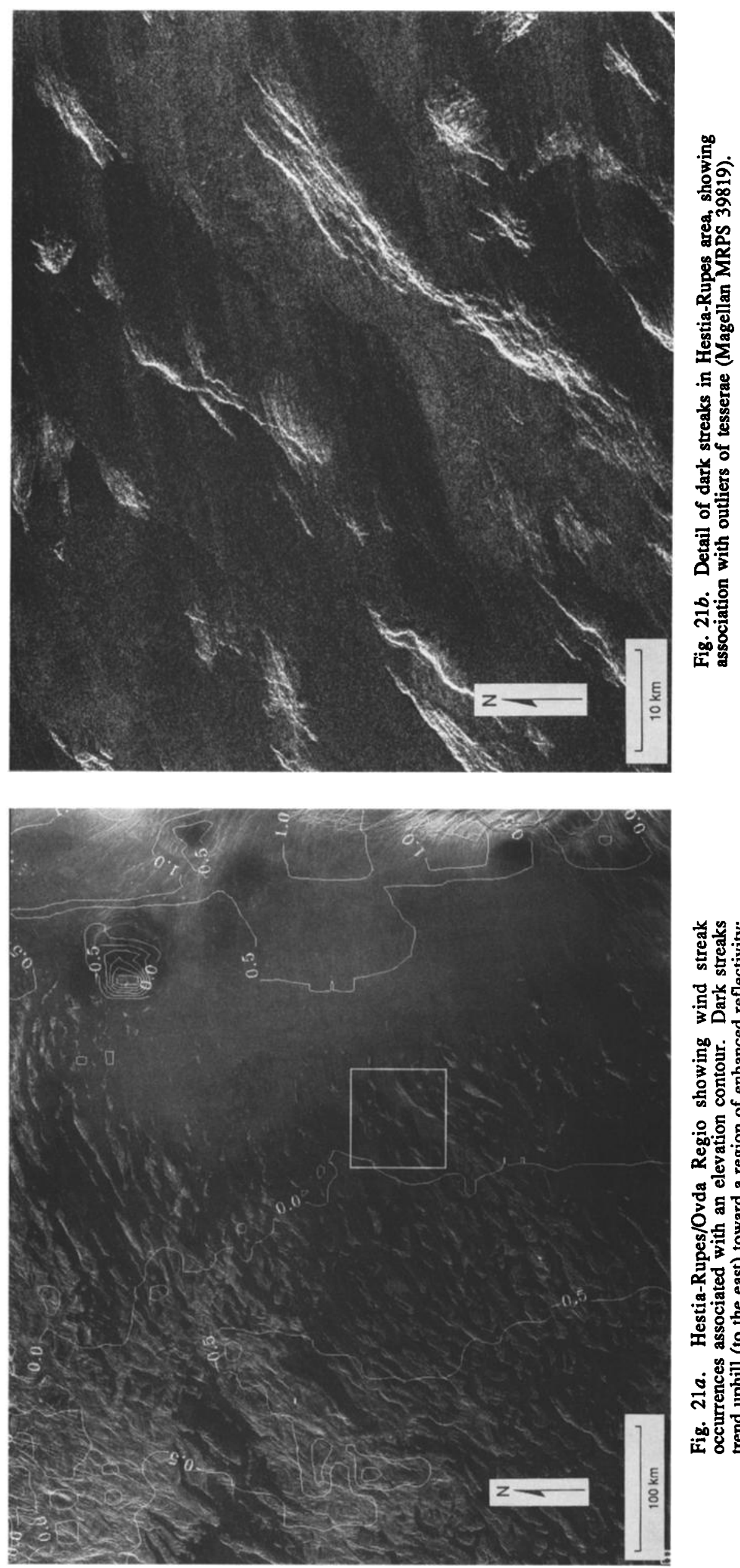

ฮै 苛苛 के क्षे 可产焉 ดั .ำ. 政 응 동 की 응홍 형 జ \% 웡 कृ 들ํํㅇ 현 政 可要焉 政 敬曹

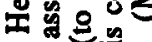
造: 可兘总 NG

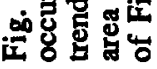


Acknowledgements. We wish to thank the following for their contributions to this report: R. Blom and T. Farr for helpful discussions, D. Ball for photographic support, E. Lo for computational support, S. Selkirk for figure preparation, and S. Blixt for word processing. The Magellan Project and parts of the research described here are carried out by the Jet Propulsion Laboratory, California Institute of Technology, under contract from the National Aeronautics and Space Administration, and through contracts to individuals: JPL-958880 (Greeley) JPL958496 and NAGW 1874 (Schubert), and JPL-957415 (Arvidson). Support for Plaut was provided by the National Research Council under the Research Associate Program.

\section{REFERENCES}

Antsibor, N.M., et al., Estimates of wind velocity and of instruments dropped from Venera 9 and Venera 10, Cosmic Res., Engl. Transl, 14, 625-631, 1976.

Arvidson, R.E., V.R. Baker, C. Elachi, S. Saunders, and J.A. Wood, Magellan: Initial analysis of Venus surface modification, Science, 252, 270-275, 1991.

Arvidson, R.E., R. Greeley, M. Malin, R.S. Saunders, N. Izenberg, j.J. Plaut, and E. Stofan, Surface modification of Venus as inferred from Magellan observations of plains and tesserae, J. Geophys. Res., this issue.

Avduevskii, F.S., et al., Measurement of wind velocity on the surface of Venus during the operation of stations Venera 9 and Venera 10, Cosmic Res., Engl. Transl., 14, 622-625, 1976.

Bagnold, R.A., The Physics of Blown Sand and Desert Dunes, 265 p., Methuen and Co., Ltd., London, 1941.

Blom, R., and C. Elachi, Spaceborne and airborne imaging radar observations of sand dunes, J. Geophys. Res., 86, 3061-3073, 1981.

Blom, R., and C. Elachi, Multifrequency and multipolarization radar scatterometry of sand dunes and comparison with spacebome and airborne radar images, J. Geophys. Res., 92, 7877-7889, 1987.

Campbell, M., and J. Ulrichs, Electrical properties of rocks and their significance for lunar radar observations, J. Geophys. Res., 74, 5867-5881, 1969.

Counselman, C.C., III, S.A. Gourevitch, R.W. King, G.B. Loriot, and R.G. Prinn, Venus winds are zonal and retrograde below the clouds, Science, 205, 85-87, 1979.

Counselman, C.C., III, S.A. Gourevitch, R.W. King, G.B. Loriot, and E.S. Ginsberg, Zonal and meridional circulation of the lower atmosphere of Venus determined by radio interferometry, J. Geophys. Res., 85, 8026-8030, 1980.

Covey, C., R.L. Walterscheid, and G. Schubert, Dissipative tides: Application to Venus' lower atmosphere, J. Atmos. Sci., 43, 3273-3278, 1986.

Dobrovolskis, A.R., and A.P. Ingersoll, Atmospheric tides and the rotation of Venus. 1. Tidal theory and the balance of torques, Icarus, 41, 1-7, 1980.

Elachi, C., et al., Shuttle imaging radar (SIR-A) experiment: Preliminary results, Science, 218, 996-1003, 1982.

Elachi, C., L. Roth, and G. Schaber, Spaceborne radar subsurface imaging in hyperarid regions, IEEE Trans. Geosci. and Remote Sens., GE-22, 383-388, 1984.

Garvin, J.B., The global budget of impact-derived sediment on Venus, Earth Moon Planets, 50/51, 175-190, 1990.

Garvin, J.B., J.W. Head, and L. Wilson, Magma vesiculation and pyroclastic volcanism on Venus, Icarus, 52, 365-372, 1982.

Garvin, J.B., J.W. Head, and S.H. Zisk, On the origin of higher radar reflectivity surfaces on Venus (abstract), Lunar Planet. Sci., 16, 266-267, 1985.

Greeley, R., Aeolian landforms: Laboratory simulations and field studies, in Aeolian Geomorphology, edited by W.G. Nickling, pp. 195-211, Allen and Unwin, Boston, Mass., 1986.
Greeley, R., and R. Arvidson, Aeolian processes on Venus, Earth Moon Planets, 50/51, 127-157, 1990.

Greeley, R., and J.D. Iversen, Wind as a Geological Process, pp. 133-197, Cambridge University Press, New York, 1985.

Greeley, R., and J.D. Iversen, Aeolian processes and features at Amboy lava field, California, Physics of Desertification, edited by F. El-Baz and M.H.A. Hassan, pp. 290-316, Martinus Nijhoff Dordrecht, Netherlands, 1986.

Greeley, R., and J.D. Iversen, Measurements of wind friction speeds over lava surfaces and assessment of sediment transport, Geophys. Res. Lett., 14, 925-928, 1987.

Greeley, R., J.D. Iversen, J.B. Pollack, N. Udovich, and B. White, Wind tunnel simulations of light and dark streaks on Mars, Science, 183, 847-849, 1974.

Greeley, R., Y. Asmerom, and S. Barnett, Radar signatures of wind streaks: Preliminary SIR-A analysis, Lunar Planet. Sci., $X I V, 259-260,1983$.

Greeley, R., J. Iversen, R. Leach, J. Marshall, B. White, and S. Williams, Windblown sand on Venus: Preliminary results of laboratory simulations, Icarus, 57, 112-124, 1984.

Greeley, R., P. Christensen, and R. Carrasco, Shuttle radar images of wind streaks in the Altiplano, Bolivia, Geology, 17, 665-668, 1989.

Greeley, R., N. Lancaster, S. Lee, and P. Thomas, Martian aeolian processes, sediments, and features, in Mars, University of Arizona Press, Tucson, in press, 1992.

Greeley, R., J.R. Marshall, D. Clemens, A.R. Dobrovolskis, and J.B. Pollack, Venus: Concentrations of radar-reflective minerals by wind, Icarus, 90, 123-128, 1991.

Head, J.W., and L. Wilson, Volcanic processes and landforms on Venus: Theory, predictions and observations, $J$. Geophys. Res., 91, 9407-9446, 1986.

Iversen, J.D., and R. Greeley, Martian crater dark streak lengths: Explanation from wind tunnel experiments, Icarus, 58, 358362,1984

Iversen, J.D., and B.R. White, Saltation threshold on Earth, Mars, and Venus, Sedimentology, 29, 111-119, 1982.

Kálney de Rivas, E., Numerical models of the circulation of the atmosphere of Venus, J. Atmos. Sci., 31, 763-779, 1973.

Kálney de Rivas, E., Further numerical calculations of the circulation of the atmosphere of Venus, J. Atmos. Sci., 32, 1017-1024, 1975.

Keldysh, M.V., Venus exploration with the Venera 9 and Venera 10 spacecraft, Icarus, 30, 605-625, 1977.

Kerzhanovich, V.V., and M.Ya. Marov, The atmospheric dynamics of Venus according to Doppler measurements by the Venera entry probes, in Venus, edited by D.M. Hunten, $L$. Colin, T.M. Donahue, and V.I. Moroz, pp. 766-778, University of Arizona Press, Tucson, 1983.

Kerzhanovich, V.V., Yu.F. Makarov, M.Ya. Marov, E.P. Molotov, M.K. Rozhdestvenskii, V.P. Sorokin, N.M. Antsibor, V.D. Kustodiev, and V.I. Puchkov, An estimate of the wind velocity and turbulence in the atmosphere of Venus on the basis of reciprocal Doppler measurements by the Venera 11 and Venera 12 spacecraft, Cosmic Res., Engl. Transl., 17, 569. 575, 1979.

Lee, S.W., Mars: Wind streak production as related to obstacle type and size, Icarus, 58, 339-357, 1984.

Marov, M., V. Avduevskii, V. Kerzhanovich, M.K. Rozhdestvenskii, N. Borodin, and O. Ryabov, Venera 8: Measurements of temperature, pressure, and wind velocity on the illuminated side of Venus, J. Almos. Sci., 30, 12101214, 1973.

Marshall, J.R., G. Fogleman, R. Greeley, R. Hixon, and D. Tucker, Adhesion and abrasion of surface materials in the Venusian aeolian environment, J. Geophys. Res., 96, 19311947, 1991. 
McCall, G.J.H., Possible meteorite craters--Wolf Creek, Australia and analogs, Science, 123, 970-998, 1965.

McCauley, J.R., M.J. Grolier, and C.S. Breed, Yardangs, in Geomorphology in Arid Regions, Proceedings 8th Geomorphology Symposium, edited by D.O. Doehring, pp. 233-269, Allen and Unwin, Boston, Mass., 1977.

Moroz, V.I., The atmosphere of Venus, Space Sci. Rev., 29, 3 127, 1981.

Pettengill, G.H., P.G. Ford, and S.D. Nozette, Venus: Global surface radar reflectivity, Science, 217, 640-642, 1982.

Pettengill, G.H., P.G. Ford, and S.D. Nozette, Venus: Evidence for high dielectric constants in elevated regions (abstract), Lunar Sci., 14, 602-603, 1983.

Pettingill, G.H., P.G. Ford, W.T.K. Johnson, R.K. Raney, and L.A. Soderblom, Magellan: Radar performance and data products, Science, 252, 260-265, 1991.

Pettingill, G.H., P.G. Ford, and R.J. Wilt, Venus surface radiothermal emission as observed by Magellan, J. Geophys. Res., this issue.

Phillips, R.J., R.E. Arvidson, J.M. Boyce, D.B. Campbell, J.E. Guest, G.G. Schaber, and L.A. Soderblom, Impact craters on Venus: Initial analysis from Magellan, Science, 252, 288-297, 1991.

Phillips, R.J., R.R. Herrick, R.E. Grimm, R.L. Raubertas, I.C. Sarkar, R.E. Arvidson, and N. Izenberg, Impact crater distribution on Venus: Implication for planetary resurfacing history, J. Geophys. Res., this issue.

Rossow, W.B., A general circulation model of a Venus-like atmosphere, J. Atmos. Sci., 40, 273-302, 1983.

Sagan, C.A., J. Veverka, P. Fox, R. Dubisch, J. Lederberg, E. Levinthal, L. Quam, R. Tucker, J.B. Pollack, and B.A. Smith, Variable features on Mars: Preliminary Mariner 9 television results, Icarus, 17, 346-372, 1972.

Sagan, C., J. Veverka, P. Fox, R. Dubisch, R. French, P. Gierasch, L. Quam, J. Lederberg, E. Levinthal, R. Tucker, B. Eross, and J.B. Pollack, Variable features on Mars, 2. Mariner 9 global results, J. Geophys. Res., 78, 4163-4196, 1973.

Saunders, R.S., A.R. Dobrovolskis, R. Greeley, and S.D. Wall, Large-scale patterns of eolian sediment transport on Venus: Predictions for Magellan, Geophys. Res. Lett., 17, 1365 1368, 1990.

Saunders, R.S., R.E. Arvidson, J.W. Head III, G.G. Schaber, E.R. Stofan, and S.C. Solomon, An overview of Venus geology, Science, 252, 249-252, 1991.

Saunders, R.S., et al., Magellan mission summary, J. Geophys. Res., this issue.

Schaber, G.G., R.G. Strom, H.J. Moore, L.A. Soderblom, R.L. Kirk, D.J. Chadwick, D.D. Dawson, L.R. Gaddis, J.M. Boyce, and J. Russell, Geology and distribution of impact craters on Venus: What are they telling us?, J. Geophys. Res., this issue.

Schubert, G., General circulation and the dynamical state of the

Venus atmosphere, in Venus, edited by D.M. Hunten, L. Colin, T.M. Donahue, and V.I. Moroz, pp. 681-765, University of Arizona Press, Tucson, 1983.

Schubert, G., et al., Structure and circulation of the Venus atmosphere, J. Geophys. Res., 85, 8007-8025, 1980.

Stone, P.H., The structure and circulation of the deep Venus atmosphere, J. Atmos. Sci., 31, 1681-1690, 1974.

Stone, P.H., The dynamics of the atmosphere of Venus, $J$. Atmos. Sci., 32, 1005-1016, 1975.

Thomas, P., and J. Veverka, Seasonal and secular variation of wind streaks on Mars: Analysis of Mariner 9 and Viking data, J. Geophys. Res., 84, 8131-8146, 1979.

Thomas, P., J. Veverka, S. Lee, and A. Bloom, Classification of wind streaks on Mars, lcarus, 45, 124-153, 1981.

Thomas, P., J. Veverka, D. Gineris, and L. Wong, "Dust" streaks on Mars, Icarus, 60, 161-179, 1984.

Tyler, G.L., P.G. Ford, D.B. Campbell, C. Elachi, G.H. Pettengill, and R.A. Simpson, Magellan: Electrical and physical properties of Venus' surface, Science, 252, 265-270, 1991.

Veverka, J., C. Sagan, and R. Greeley, An unusual crater streak in Mesogaea, Icarus, 27, 241-253, 1976.

Veverka, J., P. Thomas, and R. Greeley, A study of variable features on Mars during the Viking primary mission, $J$. Geophys. Res., 82, 4167-4187, 1977.

Veverka, J., P. Gierasch, and P. Thomas, Wind streaks on Mars: Meteorological control of occurrence and mode of formation, Icarus, 45, 154-166, 1981.

Ward, W., and R. Greeley, Evolution of the yardangs at Rogers Lake, Califomia, Geol. Soc. Am. Bull., 95, 829-837, 1984.

R.E. Arvidson, Department of Earth and Planetary Sciences, Washington University, One Brookings Drive, St. Louis, MO 63130-4899.

C. Elachi, J.J. Plaut, R.S. Saunders, E.R. Stofan, E.J.P. Thouvenot, S.D. Wall, and C.M. Weitz, Jet Propulsion Laboratory, 4800 Oak Grove Drive, Pasadena, CA 91109.

M.A. Geringer and R. Greeley, Department of Geology, Arizona State University, Tempe, AZ 85287-1404.

G. Schubert, Department of Earth and Space Sciences, IGPP, University of California, Los Angeles, CA 90024-1567.

(Received September 27, 1991; revised April 27, 1992; accepted April 28, 1992.) 